\title{
Restoring Drying Lakes with Treated Agricultural Effluents under a Carbon-based Payments for Ecosystem Services Incentive
}

ram ranjan ( $\square$ ram.ranjan.work@gmail.com )

Shiv Nadar University School of Humanities and Social Sciences https://orcid.org/0000-0002-87569392

\section{Research Article}

Keywords: Drying lakes, constructed wetlands, carbon release, payments for ecosystem services, agricultural effluents, carbon sequestration

Posted Date: April 14th, 2021

DOI: https://doi.org/10.21203/rs.3.rs-347809/v1

License: (a) (i) This work is licensed under a Creative Commons Attribution 4.0 International License.

Read Full License 


\title{
Restoring Drying Lakes with Treated Agricultural Effluents under a Carbon-based
} Payments for Ecosystem Services Incentive

\author{
Ram Ranjan \\ Department of Economics \\ School of Humanities and Social Sciences \\ Shiv Nadar University, Greater Noida, Uttar Pradesh, India \\ Ph: +91-0120-7170100 Extn: 194; Email: ram.ranjan@snu.edu.in \\ ORCID ID: 0000-0002-8756-9392
}

\section{Abstract}

Wetlands store a significant proportion of terrestrial carbon, however, when degraded and dry, they can become net carbon emitters. Climatic stressors, such as rising temperature and reduced precipitation, further exacerbate carbon release risks. This study explores incentivizing adoption of constructed wetlands $(\mathrm{CW})$ on agricultural farms for treating effluents and releasing into drying lakes. A payment for ecosystem services (PES) framework is developed to analyze land use allocation decisions of farmers towards adopting CWs on their private farms. Release of treated agricultural wastewater helps a drying lake remain wet under a warming climate preventing release of carbon stored in its soils. Results indicate that PES payments equaling 10,000 to 20,000 INR (150-300 US dollars) per mega litre (ML) can be effective in incentivizing adoption of CWs on farms in India, and their benefits to drying lakes can be significant. Specifically, life of lakes can be prolonged to more than 100 years under such PES based schemes besides resulting in substantial carbon storage in soils. Such PES schemes can be a cost-effective way to not only protect and conserve lakes for their biodiversity and livelihood benefits but also from a carbon mitigation perspective. Results further show that when a social planner allocates land between farming and $\mathrm{CW}$, incorporating the carbon sequestration benefits of lakes and when facing a risk of abrupt and permanent drying of lakes, their adoption rate is higher compared to that of the farmers. When extrapolated, carbon benefits from such PES programs for the entire country could be nearly 15 trillion USD over the next 100 years.

Keywords: Drying lakes; constructed wetlands; carbon release; payments for ecosystem services; agricultural effluents; carbon sequestration 


\section{Introduction}

31 Wetlands occupy about 12 million $\mathrm{km}^{2}$ of global geographical area (Moomaw et al., 2018). They

32 also store the most amount of carbon in the biosphere at nearly $30 \%$ of the total $15 \mathrm{Pg}$ soil carbon

33 (Nahlik and Fennessy, 2016). In the United States, there is about 10 times more carbon (at 9.6

$34 \mathrm{x} 10^{15} \mathrm{~g} \mathrm{C}$ ) stored in wetlands than in tidal saltwater sites (Braun et al., 2019). However, owing to

35 anthropogenic pressures, the planet has been losing wetlands at a rapid pace. Since $1700 \mathrm{AD}$, we

36 have lost $87 \%$ of the world's wetlands (Davidson, 2014). In the $20^{\text {th }}$ century, coastal wetlands

37 globally declined at a rate of $0.7-1.2 \%$ annually resulting in more than $60 \%$ loss to their total area.

38 The loss in coastal wetlands has been highest in Asia at 1.1\%, whereas in Europe it has been $0.99 \%$

39 and $0.51 \%$ in America (Lin and Yu, 2018). In China, wetlands are being lost at a rate of $10 \mathrm{~km}^{2} / \mathrm{yr}^{2}$

40 (Hu et al., 2019).

In India, more than a third of existing wetlands have been lost due to encroachment,

42 urbanization, land use changes and warming temperatures. Wetlands in India occupy almost 5\%

43 of the country's geographical area. Currently India is losing wetlands at a rate of 2-3\% per year

44 (Prasher, 2018). Foote et al. (1996) identified 12 major causes of wetland loss in India, including

45 agricultural conservation, deforestation, hydrological alteration, water quality degradation,

46 wetland consolidation and groundwater extraction. More than 50,000 wetlands in India have been

47 rendered dead from water pollution alone (Prasad et al., 2002). Owing to urban expansion and

48 encroachment, in Mumbai, more than $70 \%$ of wetlands have been lost over the past four decades

49 (Chauhan, 2020). Similarly, lake Shambhar in Rajasthan faces extinction threats due to

50 encroachment and groundwater extraction (Rana, 2019). Whereas Karanji lake in Mysuru, India

51 has completely dried up (Milton, 2019). 
Warming temperatures are further projected to cause an increase in lake water evaporation

53 rate over the course of this century (Wang et al., 2018). Based on IPCC's A1B scenario, climate

54 change could cause significant drying of Montane wetlands in the US Pacific Northwest (Lee et

55 al., 2015). Similarly, warming temperatures and reduced precipitation are expected to decrease

56 wetlands in Canada by between 7 and 47\% (Withey and van Kooten, 2011). Due to frequent

57 drought conditions, Chad and Urmia lakes in Africa have shrunk by $80 \%$ and 65\% (Smith, 2012).

58 Warming temperatures also increase the risk of fires. The great Dismal Swamp sequesters

59 significant amounts of carbon, however catastrophic fires can cause a release of 6.5 million tonnes

60 of $\mathrm{CO}_{2}$ and a net present value (NPV) of losses amounting to more than 200 million USD (Pindilli

61 et al., 2017).

Climate change is also increasing the frequency of droughts, causing several wetlands to go dry temporarily and permanently. Dry wetlands can become net emitters of methane and carbon

64 (Petrescu et al., 2015; Stirling et al., 2020). Degraded wetlands have been found to be net carbon 65 emitters and their restoration can be 100 times more cost-effective as compared to alternative 66 carbon mitigation options (Were et al., 2019). Restored wetlands in Illinois, USA sequestered 67 between 25 and $45 \%$ more carbon compared to degraded ones after 3 years of restoration (Were 68 et al., 2019). The difference in sequestration rate further improved to more than $50 \%, 10$ years 69 after degradation. Whereas a meta-analysis of more than 600 wetlands globally found that the 70 sequestration rate in restored wetlands remained about $25 \%$ lower compared to undegraded 71 wetlands (Moreno-Mateos et al., 2012). Further, restoration benefits only start to manifest after a 72 certain point of time, resulting in time lag costs of forgone benefits to society. In Ohio, USA, the 73 average time lag cost of restored wetlands has been estimated at about 16,000 USD per acre 74 (Gutrich et al., 2004). Similarly, in Colorado, time-lag costs in terms of mitigation wetlands 
75 reaching full floristic equivalency have been estimated at about 27,000 USD/acre (Gutrich et al.,

76 2004). Therefore, it is important to prevent degradation of wetlands in order for society to

77 maximize benefits from carbon mitigation efforts.

There exists a significant body of work in the literature dealing with the determinants of

79 wetland loss as well as analyzing the use of existing and new policy tools for their protection.

80 Section 404 of the Clean Water Act in the United State mandates that for every wetland that is lost

81 due to draining, a new wetland must be created to offset the services provided by the lost wetland

82 (Ribaudo et al., 2009). As a result, there are currently more than 600 mitigation banks in the US

83 that provide credits for wetland restoration which can be sold to developers who destroy wetlands.

84 Similarly, the possibility of using environmental impact bonds for restoring wetlands in Louisiana

85 has been explored by Herrera et al, (2019). Under this scheme, investors pay in advance for

86 restoration projects however, their returns are guided by the degree of environmental outcome

87 achieved. Carbon credits for conservation efforts have also been promoted. Nath and Lal (2016)

88 explored the possibility of managing global wetlands towards rice output expansion while

89 simultaneously promoting soil organic carbon conservation in the littoral zones. Further, society's

90 valuation of wetlands could be capitalized towards investment in wetland preservation initiatives.

91 Birol et al., (2006) performed choice experiments to assess the value of Cheimaditida wetland in

92 Greece through willingness to pay (WTP) of respondents. They found that the aggregate net benefit

93 of attaining wetland restoration (respondents' WTP minus the costs of restoration program) was

94 about 3 million euros.

Agricultural expansion is one of the key stressors of wetlands globally. Farmers' 96 perceptions related to the value of wetlands may differ significantly from other stakeholders such

97 as the government, fishermen and wetland non-users. In the Rushebey-Kanyabaha wetland of 
98 southwest Uganda, farmers perceived agricultural expansion in the wetland area to be beneficial

99 for their livelihoods whereas wetland non-users expressed a strong preference towards wetland 100 conservation (Bosma et al., 2017). Whereas in a Swedish catchment-based wetland creation 101 program, farmers expressed their willingness to voluntarily participate for private profit as well 102 public environmental benefits related reasons (Soderqvist, 2003). Similarly, in China, creating 103 better awareness about the ecological benefits of wetlands amongst farmers reduced the required 104 compensation payments and overall restoration costs (Wei et al., 2021). A meta-analysis of 78 105 studies revealed that participation in PES programs increased with ownership of capital assets such 106 as land endowments and financial wealth (Jones et al., 2020).

Given that agriculture directly and indirectly poses a significant threat to wetlands, the 108 solution to their conservation must also be explored within that sector. For instance, farmers could 109 be incentivized to reduce effluent loadings into streams that end up in wetlands. Heberling et al. 110 (2010) explore the use of wetlands in reducing nutrients in water streams through water quality 111 trading-based incentives in the United States. Wetlands also sequester large amounts of carbon, 112 which could be further promoted through payments for ecosystem services (PES) incentives. 113 Several studies have explored carbon mitigation value of wetlands. The Wetland Reserve Program 114 (WRP) in the Mississippi Alluvial Valley generates an annual carbon mitigation value of between 115177 and $222 \mathrm{USD} /$ ha through restoration of degraded wetlands (Jenkins et al., 2010). Wetlands in 116 Nova Scotia have been estimated to sequester on average of 4.99 tons/ha/yr of carbon, yielding a 117 value of $\$ 124-373 / \mathrm{ha} / \mathrm{yr}$ or a total value of 10 billion Canadian dollars (Gallant et al., 2020). Apart 118 from carbon benefits, flood protection services of wetlands can also be substantial (Calder et al., 119 2019). 
While carbon mitigation potential of wetlands has been widely recognized, there are few 121 programs that incentivize farmers to adopt best management practices on farms that could result

122 in higher carbon sequestration in wetlands. The use of constructed wetlands (CWs) is increasingly 123 being promoted for treating agricultural effluents and industrial wastewater (National Research 124 Council, 2012; Wang et al., 2018; Garcia et al., 2020). In coastal catchments of Stockholm Sweden, $12530 \%$ of surveyed farmers in a choice experiment study were willing to create wetlands on their 126 farms to mitigate eutrophication of waterbodies (Franzen et al., 2016). However, their use for 127 protecting natural lakes from drying and preventing release of carbon under future warming 128 scenarios remains unexplored thus far. Recognizing this gap, we propose a PES framework that 129 130 water quality and volume, thereby reducing the risk of future drying and carbon loss. Release of treated agricultural effluents would ensure that the lake would have water even in drought years 134 and would avoid irreversible degradation and loss. Landowners converting nutrient rich effluents 135 into cleaner water could get paid carbon credits based on the volume of water discharged into the 136 lake. If the lake became dry, it would turn into a net carbon emitter, resulting in long term societal 137 damages. Further, a dry lake is more likely to get encroached upon or being temporarily used for 138 growing crops. This could result in release of all carbon stored in the soil. When faced with such 139 risks, the socially optimal water pollution abatement effort would be higher than what may be 140 possible through water quality trading programs that are operational in some parts of world today. In this study, a dynamic optimization model of $\mathrm{CW}$ adoption on agricultural farms is 142 developed keeping in mind the long run benefits of releasing treated effluent water into the lake. 
143 Water released into the lake from farms helps mitigate the effects of a warming climate, which is

144 projected to cause increasing evapotranspiration rates over the course of the century. Optimal rate

145 of CW adoption is compared from private farmers' and the social planner's perspective, where the

146 latter also incorporates the risk of carbon release from a sudden drying of the lake. Implications

147 on carbon sequestration and loss prevention are derived under several scenarios. This study

148 contributes to the PES literature through demonstrating how financial incentives could be utilized

149 to get farmers directly involved in carbon mitigation objectives while simultaneously benefiting

150 wetland biodiversity and community livelihoods. It also adds to the literature dealing with the

151 promotion of constructed wetlands through linking adoption of CWs on private farms to the

152 protection of natural wetlands.

2. Model

\subsection{Background}

156 Consider that farmers in a community adopt CW technology on their individual farms. Farmers

157 are assumed homogenous with respect to their land size, quality and crop choices so that a 158 representative farmer can make land use and CW adoption decisions for the entire community. 159 CWs on individual farms are connected through a drainage canal to a main channel that empties 160 into the natural lake. The irrigation water used for farming is treated in the CWs before being 161 released into the canal. Assuming a water scarce world, farmers do not extract groundwater for 162 irrigating their crops as groundwater levels are too low. It is further assumed that the groundwater 163 aquifer is not linked to the wetland so that a reduction in the groundwater levels does not impact 164 on lake water storage. Under a PES mechanism, the farmer is paid for carbon sequestered due to 165 enhanced water availability in the wetland. Optimal CW investment is also derived from a social 
166 planner's perspective. In addition to farmer's welfare, the social planner considers the possibility

167 of carbon loss in case of future drying of like due to climate change or encroachment. Next, we

168 set up the formal model.

$169 \quad$ 2.2.Model

170 Agricultural output $q_{t}$, at time $t$, is given as:

171

(1) $q_{t}=q_{0} \frac{\left(r_{t}(1-\varphi)\right)^{\alpha_{0}}}{\left(r_{t}(1-\varphi)\right)^{\alpha_{0}}+\alpha_{1}}$

172 where $q_{0}$ is the maximum possible output per unit area (say tons/ha) irrespective of the level of

173 rainwater $r_{t}$ applied. Parameter $\varphi$ is the rainfall runoff and $\alpha_{0} \& \alpha_{1}>0$ are parameters that

174 determine a non-linear increase in crop output with water application. Total agricultural income

$175 \pi_{t}$ is determined as a function of crop output per ha:

176

(2) $\pi_{t}=\pi_{0} q_{t} a_{t}$

177 where $\pi_{0}$ is the net price of the crop per ton and $a_{t}$ is the total area under farming at time $t$.

178 Agricultural area shrinks from conversion to CWs given as:

$179 \quad$ (3) $\dot{a}_{t}=-i_{t}$

180 where $i_{t}$ is the investment in $\mathrm{CW}$ area at time $t$. Whereas cumulative $\mathrm{CW}$ area $b_{t}$ improves with

181 annual investment $i_{t}$ given as:

$182 \quad$ (4) $\dot{b_{t}}=i_{t}$

183 Cost $m_{t}$ of CW adoption is non-linear in the area converted (Gkika, 2015), given as:

184

(5) $m_{t}=\beta_{0} i_{t}^{\beta_{1}}$ 
185 where, $\beta_{0}>0, \beta_{1}>0$ are parameters of the cost function which vary across regions. The volume 186 of effluent $e_{t}$ treated per period is a function of the total installed capacity (Juwarkar et al., 1995) 187 given by the area $b_{t}$ as:

(6) $e_{t}=\min \left(b_{t} \gamma, r_{t} \varphi a_{t} \varepsilon\right)$

189 where $\gamma$ is the treatment capacity per ha of CW plant and $\varepsilon$ is a parameter converting daily rainfall 190 on a ha of land into ML. Total volume of treated wastewater cannot exceed the maximum capacity 191 of the CW plants, given by $b_{t} \gamma$. Whereas $r_{t} \varphi a_{t} \varepsilon$ is the actual runoff water available for treatment 192 from the total area under farming. Therefore, in equation (6), the per period treatment possible 193 from $\mathrm{CW}$ plants would be the minimum of the maximum treatment capacity and the actual 194 wastewater available. In case there is excess wastewater compared to the treatment capacity in any 195 period, it is prevented from entering the canal connecting to the lake.

196 The wastewater treated by CW plants is discharged into the lake through canals resulting in 197 augmentation of lake water volume $w_{t}$ as: (7) $\dot{w}_{t}=e_{t}-\theta w_{t}-v_{t} \tau+r_{t} \delta g$

199 where $g$ is fixed lake area, $v>0$ is the rate of evapotranspiration loss in each time $t, \tau>$ 2000 is a parameter converting evaporation in mm per day per ha to ML per year, $1>\theta>0$ is 201 the fraction of lake water that is lost due to overflow and groundwater seepage and $\delta>0$ is a 202 parameter converting rain falling on lake into water volume (in ML).

203 The rate of evapotranspiration of the lake water is further given as:

(8) $v_{t}=v_{0}(1+\mu t) g \tau$ 
205 where $\mu$ is the annual percentage increase in evaporation rate (following Wang et al., 2018) and $206 v_{0}>0$ is a constant evaporation rate specific to the study area. This rate is determined by several 207 factors including temperature, windspeed, vegetation and level of eutrophication in the lake, etc. 208 (US EPA, 2008).

209 The representative farmer receives PES payments $z_{t}$ based on total volume of effluents treated 210 and discharged into the wetland stream in each time:

211 (9) $\quad z_{t}=e_{t} p_{0}$

212 where $p_{0}>0$ is the PES payment per ML of treated agricultural effluent running off into the lake 213 stream. The lake, as long as it is wet, will sequester carbon at a constant rate $\sigma$ given as (Kangabam 214 et al., 2016; Sankar and Das, 2020):

215 (10) $\quad \dot{c_{t}}=\sigma$

216 where $\dot{c}_{t}$ is the rate of change of carbon stored in wetland soil. In a dry state, there is a constant 217 rate of carbon loss, which is some fraction of the sequestration rate (Miao et al., 2013):

$$
\text { (11) } \quad \dot{c_{t}}=-\omega \sigma
$$

219 where $\omega>0$ is a parameter which could take on a value higher than 1 under extreme dry conditions.

220 The farmer's total income $y_{t}$ comprises the sum of PES and crop incomes, given as:

221

$$
y_{t}=z_{t}+\pi_{t}
$$

222 The optimal control problem for the framer involves maximizing:

223

$$
\max _{i_{t}} \int_{0}^{\infty} y_{t} \exp (-\rho t) d t
$$


224 where $\rho$ is their rate of time preference. Next, consider that a social planner maximizes the income 225 of the farmer net of societal damages from carbon release in the state when the lake turns dry. The 226 optimization problem of the planner is to maximize:

$$
\max _{i_{t}} \int_{0}^{\infty} y_{t} \exp \left(-\lambda_{t}\right) \exp (-\rho t)-\dot{\lambda} \exp \left(-\lambda_{t}\right) \exp (-\rho t) x_{t} d t
$$

228 where $\dot{\lambda}$ is the instantaneous hazard rate of lake running dry, $\lambda_{t}$ is the cumulative hazard, and $x_{t}$ is 229 the net present value of future damages to society from carbon released into the atmosphere in 230 each year the lake is dry. The expected valuation of the pre- and post -dry states is derived using 231 the methodology for exponential hazard functions as given in Reed and Heras (1992).

The lake will continue to release carbon until all stored carbon stock $c_{t}$ has been released.

233 Therefore, $x_{t}$ is a function of $c_{t}$. The hazard rate of lake running dry is a function of the volume 234 of water left in the lake. At a lower volume of water, the lake runs a higher chance of suddenly 235 running dry. Apart from hydrological factors, the lake could also get drained by farmers or be used 236 for aquaculture through creation of bunds. The chances of such illegal encroachments increase 237 when the lake water level is low as it is less costly to drain the remaining water.

Lakes can abruptly turn from wet to dry state and vice versa (Shan et al., 2018). Once the lake 239 runs dry, it flips into a degraded state where various chemical processes in the soil result in higher 240 bacterial activity resulting in net carbon loss (Larsen and Alp, 2015). To incorporate a sudden 241 change in lake state from wet to dry, the risk of lake drying is modeled as a non-linear function of 242 the water volume remaining in the lake and is given as:

$$
\dot{\lambda}=\lambda_{0}\left(1-\frac{\left(\frac{w_{t}}{w_{0}}\right)^{\epsilon_{0}}}{\left(\frac{w_{t}}{w_{0}}\right)^{\epsilon_{0}}+\epsilon_{1}}\right)
$$


244 where $\lambda_{0}$ is a constant hazard parameter, $\epsilon_{0}>0, \epsilon_{1}>0$ are parameters that determine a non-linear

245 relationship between ratio of water volume at time $t$ to maximum water volume $w_{0}$ and the hazard

246 rate. The higher the ratio, the lower the hazard of lake drying.

247 The post-drying utility $u_{\text {post }}$ from damages is based on the social cost of carbon $s_{0}$ and is 248 solved through maximizing the below problem:

249

$$
u_{\text {post }}=\int_{0}^{\infty}-s_{0} \omega \sigma g \exp (-\rho t) d t
$$

250 The post-drying value function is calibrated as a non-linear function of stock of carbon through

251 fitting the various utilities $u_{\text {post }}$ obtained for each starting stock of carbon in the lake at the time 252 of drying, and is given as:

253

$$
x_{t}=\emptyset_{0} c_{t}^{\emptyset_{1}}
$$

254 where $\emptyset_{0}>0, \emptyset_{1}>0$ are parameters of the non-linear damage function.

\section{Numerical Application}

257 A numerical application of the above model is presented in this section. A representative lake

258 from the state of Uttar Pradesh in India is considered for parameter estimation. Relevant literature 259 supporting estimation of parameter values is discussed in section 3.1 and results are presented in 260 section 3.2.

262 Estimates over carbon sequestration rates in lakes vary considerably, ranging from $230 \mathrm{~kg} \mathrm{C} / \mathrm{ha} / \mathrm{yr}$ 263 (Moomaw et al., 2018) to $4000 \mathrm{~kg} \mathrm{C} / \mathrm{ha} / \mathrm{yr}$ (Were et al., 2019). Lakes tend to sequester more carbon 
264 as they age, whereas newly created lakes can be net emitters due to higher methane emissions. In

265 the natural wetland systems of Ohio and Costa Rica, C sequestration rate has been estimated

266 between 220-270 g C/m²/yr (Mitch et al., 2012). Carbon sequestration in wetlands is sensitive to

267 water levels, and dry wetlands or those converted into croplands can turn into significant net C

268 emitters (Petrescu et al., 2015). Restoration of degraded wetlands in China can sequester between

269100 and $200 \mathrm{~kg} \mathrm{C} / \mathrm{ha} / \mathrm{yr}$ resulting in an overall $\mathrm{C}$ storage of $0.014-0.028 \mathrm{Pg} \mathrm{C} / \mathrm{yr}$ whereas

270 restoration of drained wetlands in Europe can result in even higher sequestration at $4000 \mathrm{~kg} \mathrm{C} / \mathrm{ha} / \mathrm{yr}$

271 (Were et al., 2002). Carbon release from wetland soils is sensitive to temperature changes and

272 precipitation (Miao et al., 2013). Carbon efflux in wetlands of Southeastern United States have

273 been noted to be higher during dry periods at almost 11 tons/ha/yr (Miao et al., 2013). Carbon loss

274 rate in soils doubles with every 10-degree Celsius increase in temperature (Kangabam et al., 2012).

275 In degraded arid wetlands of Australia, adding water to wetlands in the dry phase resulted in 28-

$27680 \%$ lower carbon and methane emissions (Limpert et al., 2020).

Average annual rainfall in India is $130 \mathrm{~cm}$ (Prasad et al., 2002). Average daily rainfall in

278 Saharanpur district of Uttar Pradesh is about $2.8 \mathrm{~mm} /$ day (Krishan et al., 2012). Evaporation rate

279 in the Sukhna lake of Uttar Pradesh varies between 2 and $10 \mathrm{~mm} /$ day between January and May

280 (Khobragade et al., 2016). Global lake evaporation rate, due to increasing climate warming, is

281 expected to increase by $16 \%$ by the end of the century (Wang et al., 2018). Carbon storage and

282 sequestration rates in lakes in India vary considerably. The loktak lake in Manipur, which is a

283 Ramsar site, has soil organic carbon storage of $51,800 \mathrm{~kg} / \mathrm{ha}$ and annual carbon sequestration in

284 the lake is estimated at 8 tons/ha/yr (Kangabam et al., 2016). Whereas in Chatla lake of Assam,

285 stored carbon has been estimated at about 22 tons/ha (Sarkar and Das, 2020). Annual carbon

286 sequestration in the lake is estimated at 6.3 tons/ha/yr (Sarkar and Das, 2020). 

representative region in the state of Uttar Pradesh is selected for analysis. Uttar Pradesh has large number of lakes, and many wetlands face extinction threats due to urbanization, agricultural encroachment and effluent loadings. A representative wetland, 100 ha area and depth $2 \mathrm{~m}$, is selected for analysis. Daily rainfall in the representative lake's catchment and nearby farming

292 region is assumed at $2.8 \mathrm{~mm}$ (Krishan et al., 2012), whereas daily evaporation rate is taken at 3

$293 \mathrm{~mm}$ (Khobragade et al., 2016). Rate of carbon sequestration in the lake is taken at 4 tons/ha 294 (following estimates for Indian lakes as in Kangabam et al., 2016; Sarkar and Das, 2020) which 295 lies in the range of average sequestration rates in lakes in India and globally. Similarly, when dry, 296 the lake is assumed to release 4 tons/ha of carbon annually. Starting level of carbon stored in the 297 representative lake is taken at 50 tons/ha yr (Kangabam et al., 2016). A farming area of 100 ha is 298 chosen, and farmers are assumed to grow rice, relying mostly on rain for irrigation. While 299 groundwater can also be used for growing crops, we do not include it in the model to keep the 300 analysis simple, and for the fact that the model is representing a warming climate due to which 301 groundwater is significantly depleted. In the literature concerning CWs, the cost of setting up CWs 302 varies with their capacity. For instance, a $200 \mathrm{~m}^{2} \mathrm{CW}$ wastewater treatment plant located at IIT 303 Powai cost 1 million INR and had a capacity to treat 25 kld (Lukose, 2015). A CW unit with a 304 combined area of 1 ha can treat $456.25 \mathrm{ML} / \mathrm{yr}$ of wastewater effluents. The rate of time preference 305 of the farmer and the social planner is assumed at $6 \%$. The complete list of parameter values is 306 further presented in Table 1.

\subsection{Results}

The numerical example is solved using GAMS software and a time horizon of 150 years. Results are first derived for the base case which assumes no risk of sudden drying of lake. However, with 
310 increasing evaporation, the lake could still run out of water in the long run. Several associated

311 scenarios vary key parameters to explore their impact on optimal time paths of land use, CW

312 adoption and carbon storage in the lake. Next, results are presented for scenarios where there

313 exists a risk of the lake drying permanently. The risk-based scenarios are run from the perspective

314 of the social planner, whereas the base case and its associated scenarios explore optimal investment

315 in CW from the farmer's perspective.

In the base case, $\mathrm{CW}$ adoption gradually increases, taking 10 years to reach an area of

317 roughly 0.66 ha (fig 1 ). Further adoption is not necessary given the water supply side constraints

318 as the amount of rainfall limits the total drainage runoff. In the base case scenario, lake water

319 volume declines for the first 7 years due to the effect of high evaporation (fig 2). Evaporation rate

320 is also assumed to increase at a rate of $0.2 \%$ each year (or $16 \%$ over the next 80 years), which

321 would further exacerbate water loss rate from the lake (fig 3). However, adoption of CWs begins

322 to show its effect after 7 years when sufficient capacity is accumulated in treating effluents. Lake

323 volume declines from $2000 \mathrm{ML}$ in the first year to $781 \mathrm{ML}$ by year 7 and then improves to 980

324 ML by year 17. However, due to increasing climate stress from warming temperatures, there is a

325 gradual decline in the lake's water in the very long run as the lake completely dries out in 100

326 years. When $\mathrm{CW}$ area reaches $0.66 \mathrm{ha}$, there is about $300 \mathrm{ML}$ of treated effluents that is released

327 into the lake, whereas annual evaporation rate is roughly 1,100 ML from the lake in the initial

328 years but increases to 1,300 ML by year 100 . However, as the lake also receives rainfall directly,

329 the combined effect of treated wastewater and rainwater helps improve water levels for the first

33017 years, beyond which time there is a net decline. The base case also assumes that the catchment

331 area of the lake has been encroached due to human activities and there is no additional inflow into

332 the lake from those regions. In order to see the effects of a more severe warming effect, we increase 
333 the rate of change of annual evaporation to $0.4 \%$. Under this scenario, lake water improves to a 334 lesser extent from $\mathrm{CW}$ intervention, and the long run decline in water volume is faster as the lake 335 runs dry in just 60 years. Therefore, faster evaporation under a warming climate poses significant 336 threats to lakes that receive limited annual replenishment of water. The $0.4 \%$ annual evaporation 337 rate increase scenario does not have a reduced rate of $\mathrm{CW}$ adoption compared to the base case as 338 the farmer receives the same PES (10,000 INR/ML) under the two scenarios. In a scenario where there is no PES payment made, there is no incentive for the farmers to adopt CW. In fact, a smaller PES of $1000 \mathrm{INR} / \mathrm{ML}$ is also not good enough to incentivize adoption 341 as it does not cover the costs of CW technology. Therefore, under the $1000 \mathrm{INR} / \mathrm{ML}$ scenario, we 342 observe a sharp drop in the lake water volume in the lake as it dries up in just 9 years. The 343 difference between this scenario and the base case scenario highlights the role of PES incentives 344 in prolonging lake's life. As PES payments are increased from 10,000 to 20,000 and then to $345200,000 \mathrm{INR} / \mathrm{ML}$, time to full adoption (of $0.66 \mathrm{ha}$ ) reduces from 10 years to 6 years and then to 3463 years. This suggests that PES can be effective in providing immediate respite to lakes that are at 347 a higher risk of evaporation and drying. However, a higher PES can only expedite CW adoption 348 rate. When water supply is limited and $\mathrm{CW}$ adoption cannot happen beyond a certain point, long 349 run sustainability of the lake cannot be guaranteed. This is evident in comparing lake water volume 350 under low and high PES scenarios. For the first 20 years, a higher PES results in better lake volume 351 levels compared to a lower PES, however beyond that point the effect of higher evaporation takes 352 over and the lake dries out in the long run under all scenarios. The base case assumes a low rainfall 353 of $2.8 \mathrm{~mm} /$ day. An improvement in the rainfall to $4 \mathrm{~mm} /$ day can make a significant difference to 354 the long run sustainability of the lake. Under this new scenario, lake water reaches a peak volume 355 of about 3,800 ML by year 25 and starts to decline from then onwards, however, even at the end 
356 of the time horizon (which is 150 years in our model), the lake volume is still at about 2500 ML.

357 In another scenario, where rainfall is $1.8 \mathrm{~mm} /$ day, the lake survives for only 4 years. This suggests

358 that $\mathrm{CW}$ adoption needs to be promoted keeping in mind the shortfall in the long run rainfall

359 experienced by a particular region.

We next consider two scenarios from the farmer's land size and agricultural opportunity costs perspective. When the farmer owns a lower land area (of $50 \mathrm{ha}$ ), adoption rate is delayed as

362 the opportunity cost of enrolling land is higher, but more importantly, because revenues generated 363 through farming fall short of the requirements for making faster investments into CW technology.

364 When farm size is lower, agricultural income is also lower, which means that the farmer has to 365 wait longer to reach the maximum $\mathrm{CW}$ capacity. This has an adverse impact on lake water volume 366 as there is a sharp decline in its levels compared to the base case. In fact, the lake survives only 40 367 years under this scenario. Another scenario, where income from farming is 50,000 INR/ha (as 368 compared to base case income of 100,000 NIR/ha), there is a reduction in adoption rate. However, 369 under a lower income scenario, even though it reduces the rate of adoption, complete CW adoption 370 is reached in the long run. From fig 4, depicting the time path of agricultural incomes, it is clear 371 that these two scenarios result in one of the lowest agricultural incomes to the farmer, which 372 explains the low adoption rate. Also, compare PES based incomes, in fig 5, for the various 373 scenarios. For the base case, PES income is lower compared to long run agricultural income. 374 Whereas the highest PES scenario of 200,000 INR/ML far exceeds the agricultural income, which 375 explains the fastest adoption rate under this scenario.

376 Next, we consider scenarios where a social planner maximizes incomes from farming while 377 simultaneously accounting for the social costs of carbon released from drying of the lake. The risk 378 of lake drying is a function of the water level, and when the water level (or volume) falls below 
$3791000 \mathrm{ML}$, this risk increases significantly. We consider a base case risk scenario where the risk of 380 lake drying is low. Compared to the no-risk case, the presence of risk results in higher rate of CW 381 adoption by the planner (fig 6). This helps improve lake volume in the short term (fig 7). However, 382 in the long run there is decline similar to no-risk case, given the water supply constraints. When 383 the hazard rate of drying increases to 0.1 (from 0.06 ), there is a further increase in CW adoption 384 rate by the planner in order to prevent the risk from increasing through keeping the lake volume 385 higher. However, the fastest adoption happens when the planner ignores farm income in the utility 386 function and is only concerned about social costs of carbon emissions. Under this scenario, full 387 CW adoption occurs right in the first year. The impact of this early adoption on lake water volume 388 (as depicted in the figure) is higher, however, given the low rainfall scenario it is not enough to 389 protect the lake in the long run. Figure 8 depicts survival probabilities under the drying risk 390 scenarios. Given that survival probabilities are endogenous, there is a higher rate of CW adoption 391 to keep water level higher and prevent the lake from drying.

\section{Discussion}

394 Results from the numerical application of the model generate several important insights. From the 395 findings, it is clear that PES mechanism can be an attractive option to induce CW adoption on 396 private farms. PES payments of 20,000 INR/ML and 200,000 INR/ML can ensure maximum 397 capacity installation in just 6 and 3 years. However, when there is less effluent water to treat, the 398 long run sustainability of lakes cannot be ensured. This is especially true under a warming scenario 399 where lake water evaporates rapidly. Under such as scenario, despite the CW based intervention, 400 it is not possible to prolong a lake's life beyond 60 years. Similarly, when farmers' crop incomes 401 are lower or there is less land available for farming, the high financial capital necessary for CW 
402 installation can result in delayed adoption. Finally, when faced with risk of lake drying 403 permanently due to a depletion in water levels, the social planner undertakes a faster rate of CW 404 adoption as compared to the farmer. When the social planner only accounts for the social costs of 405 carbon from carbon release in the post-drying state (that is, excludes farm incomes), the rate of 406 CW adoption increases even further.

The value of the PES mechanism in terms of carbon mitigation benefits to society can be 408 judged from the fact that in absence of PES incentives the lake dries up in just 9 years, whereas 409 under PES it lasts 110 years. Therefore, under the PES initiative there is an additional carbon 410 sequestration for about 100 years, which at a rate of 4 tons/ha/yr would result in 40,000 tons of 411 extra carbon sequestration (given the lake area of $100 \mathrm{ha}$ ). In addition, damages from release of 412 carbon for the next 100 years are also avoided. Assuming a carbon release rate of 4 tons/ha from 413 dry lakes, another 40,000 tons of release is prevented. At a social cost of carbon of $\$ 34 /$ ton, total 414 value of the PES benefits in terms of carbon sequestered and avoided release would be 2.72 million 415 USD. Further assuming that a third of India's lakes (5.45 million ha in total area) may go dry in 416 the next 10 years, one can extrapolate the carbon benefits of such a PES program at nearly 15 417 trillion USD over the next 100 years. Our findings add to the existing literature on valuation of 418 stored carbon through developing innovative mechanisms for their protection. While our model 419 indicates that farmers would benefit from such PES programs promoting carbon preservation, 420 other studies have found that the impact of carbon storage may be poverty alleviating or 421 exacerbating depending upon various circumstances (Ferraro et al., 2015).

422 There are a few limitations of the modeling approach of this study which are worth mentioning.

423 The role of groundwater withdrawal on wetland water dynamics is not explicitly modeled. When 424 farming areas encroach on wetland catchments, water withdrawals and diversion for agriculture 
425 can adversely impact on wetland water levels. The model also ignores climate change induced

426 decrease in precipitation in the long term which could further aggravate the drying effect. The role

427 of additional stressors on the wetland environment, such as through fishing related encroachment

428 and draining of water for private aquaculture or irrigation have not been included. Similarly, the

429 supply of treated water to wetlands could generate substantial biodiversity values through

430 supporting fish and bird species. This would mean that the value of environmental services

431 generated by the CW adopting farmers would be higher than what has been modeled in this study.

432 There could be multiple sources through which effluents may end up in large lakes. Therefore, for

433 such a PES mechanism to work in large lakes, multiple arrangements would be required with

434 several parties, which may increase the regulatory and monitoring burden of key stakeholders. CW

435 adoption in this study is limited due to reliance upon rainfall as the main source of irrigation.

436 However, there is also possibility of using municipal wastewater effluents in CW units and

437 utilizing it on farms or releasing for the wetlands. Such an arrangement can further enhance the

438 effectiveness of PES schemes. Finally, CW units also release carbon and methane, which was not

439 accounted for in the model due to the reason that most of the carbon contained in nutrient rich

440 effluents would get released into the atmosphere in absence of CW treatment.

\section{Conclusion}

443 The planet is losing wetlands at an alarming rate. Drying wetlands pose major challenges to carbon

444 mitigation objectives through releasing large amounts of carbon stored in their soils. In this study,

445 a potential PES mechanism involving constructed wetlands was developed to help slow down the

446 loss of natural lakes through involving private parties in their conservation. Specifically, a PES

447 model derived optimal adoption rate of CWs on private farms by agricultural farmers for treating 
448 farm effluents and releasing it into a lake. Results showed that such financial incentives could 449 result in rapid adoption of CWs, helping mitigate risk of drying of lakes. Further, carbon benefits 450 provided by such PES schemes, when implemented over a third of the country's total wetland area, 451 would be nearly 15 trillion USD over the next 100 years.

452 In order for such PES mechanisms to be effectively implemented, regulatory, institutional 453 and physical infrastructure may need to be strengthened. From a regulatory perspective, release of 454 untreated effluents into water streams that end up in lakes would need to be made illegal. While 455 many countries such as the USA and India already have such regulatory mechanisms in place, $456 \quad 100 \%$ compliance has not been achieved. Investment in physical infrastructure such as canals and 457 creation of wetland boundaries would provide more incentives for farmers to invest in CWs as 458 their returns from investment would then be guaranteed for a long time. Similarly, promoting 459 collective participation in such programs would generate economies of scale through lowering the 460 costs of adopting CWs. Finally, further research is needed to assess how farmers cooperate for 461 adopting grey technologies that provide significant private and environmental benefits to society. 
464 Declarations:

$465 \quad$ Funding (Not applicable)

466 Conflicts of interest/Competing interests (the authors report no conflict of interest)

467 Ethics approval (Not applicable)

468 Consent to participate (Not applicable)

469 Consent for publication (Not applicable)

470 Availability of data and material (all data used in this research is contained within the 471 manuscript)

472 Code availability (available upon request)

473 Authors' contributions (Not applicable)

474 


\section{References}

476

477

478

479

480

481

482

483

484

485

486

487

488

489

490

491

492

493

494

495

496

497

498

499

500

501

502

503

504

505

506

507

508

509

Calder, R. S. D., Shi, C., Mason, S. A., Olander, L. P., \& Borsuk, M. E. (2019). Forecasting ecosystem services to guide coastal wetland rehabilitation decisions. Ecosystem Services, 39, 101007. https://doi.org/10.1016/j.ecoser.2019.101007

Chauhan, S. (2020). Mumbai Lost 71\% of its Wetlands In 44 Yrs, Maximum For Any Indian City. Indiatimes. Retrieved February 11, 2021, from https://www.indiatimes.com/trending/environment/mumbai-lost-71-of-its-wetlands-in-44yrs-maximum-for-any-indian-city-505527.html

Ferraro, P. J., Hanauer, M. M., Miteva, D. A., Nelson, J. L., Pattanayak, S. K., Nolte, C., \& Sims, K. R. E. (2015). Estimating the impacts of conservation on ecosystem services and poverty by integrating modeling and evaluation. Proceedings of the National Academy of Sciences of the United States of America, 112(24), 7420-7425. https://doi.org/10.1073/pnas.1406487112

Franzén, F., Dinnétz, P., \& Hammer, M. (2016). Factors affecting farmers' willingness to participate in eutrophication mitigation - A case study of preferences for wetland creation in Sweden. Ecological Economics, 130, 8-15. https://doi.org/10.1016/j.ecolecon.2016.05.019

Gkika, D., Gikas, G. D., \& Tsihrintzis, V. A. (2014). Construction and operation costs of constructed wetlands treating wastewater. Water Science and Technology, 70(5), 803-810. https://doi.org/10.2166/wst.2014.294

Gutrich, J. J., \& Hitzhusen, F. J. (2004). Assessing the substitutability of mitigation wetlands for natural sites: Estimating restoration lag costs of wetland mitigation. Ecological Economics, 48(4), 409-424. https://doi.org/10.1016/j.ecolecon.2003.10.019

Heberling, M. T., García, J. H., \& Thurston, H. W. (2010). Does encouraging the use of wetlands in water quality trading programs make economic sense? Ecological Economics, 69(10), 1988-1994. https://doi.org/10.1016/j.ecolecon.2010.05.014

Herrera, D., Cunniff, S., DuPont, C., Cohen, B., Gangi, D., Kar, D., ... Mountenot, M. (2019). Designing an environmental impact bond for wetland restoration in Louisiana. Ecosystem Services, 35, 260-276. https://doi.org/10.1016/j.ecoser.2018.12.008

Jenkins, W. A., Murray, B. C., Kramer, R. A., \& Faulkner, S. P. (2010). Valuing ecosystem services from wetlands restoration in the Mississippi Alluvial Valley. Ecological Economics, 69(5), 1051-1061. https://doi.org/10.1016/j.ecolecon.2009.11.022

Jones, K. W., Powlen, K., Roberts, R., \& Shinbrot, X. (2020). Participation in payments for ecosystem services programs in the Global South: A systematic review. Ecosystem Services, 45, 101159. https://doi.org/10.1016/j.ecoser.2020.101159 
Juwarkar, A. S., Oke, B., Juwarkar, A., \& Patnaik, S. M. (1995). Domestic wastewater treatment through constructed wetland in India. Water Science and Technology, 32(3), 291-294. https://doi.org/10.1016/0273-1223(95)00637-0

Kangabam, R., S. Kanagaraj, G. Munisamy (2016.) Assessment of carbon sequestration potential of loktak lake in manipur - a biodiversity hotspot. International Journal of Conservation Science. 7(4): 1145-1152.

Larsen, S., \& Alp, M. (2015). Ecological thresholds and riparian wetlands: an overview for environmental managers. Limnology, 16(1). https://doi.org/10.1007/s10201-014-0436-1

Lee Foote, A., Pandey, S., \& Krogman, N. T. (1996). Processes of wetland loss in India. Environmental Conservation, Vol. 23, pp. 45-54. https://doi.org/10.1017/s0376892900038248

Lee, S.-Y., Ryan, M. E., Hamlet, A. F., Palen, W. J., Lawler, J. J., \& Halabisky, M. (2015). Projecting the Hydrologic Impacts of Climate Change on Montane Wetlands. PLOS ONE, 10(9), e0136385. https://doi.org/10.1371/journal.pone.0136385

Limpert, K. E., Carnell, P. E., Trevathan-Tackett, S. M., \& Macreadie, P. I. (2020). Reducing Emissions From Degraded Floodplain Wetlands. Frontiers in Environmental Science, 8, 8. https://doi.org/10.3389/fenvs.2020.00008

Lukose, A. (2015). IIT-Bombay Team Ready with a Natural System to Treat Powai Lake Water, Indian Express, https://indianexpress.com/article/cities/mumbai/iit-bombay-team-readywith-a-natural-system-to-treat-powai-lake-water/

Miao, G., Noormets, A., Domec, J.-C., Trettin, C. C., McNulty, S. G., Sun, G., \& King, J. S. (2013). The effect of water table fluctuation on soil respiration in a lower coastal plain forested wetland in the southeastern U.S. Journal of Geophysical Research: Biogeosciences 118:1748-1762, 118, 1748-1762. https://doi.org/10.1002/2013JG002354

Milton, L. (2019). Karanji lake dries up, tourism flow hit, Times of India. Retrieved February 14, 2021, from https://timesofindia.indiatimes.com/city/mysuru/karanji-lake-dries-up-tourismflow-hit/articleshow/69549035.cms

Nahlik, A. M., \& Fennessy, M. S. (2016). Carbon storage in US wetlands. Nature Communications, 7(1), 1-9. https://doi.org/10.1038/ncomms 13835

Nath, A. J., \& Lal, R. (2017). Managing tropical wetlands for advancing global rice production: Implications for land-use management. Land Use Policy, 68, 681-685. https://doi.org/10.1016/j.landusepol.2017.08.026

National Research Council. 2012. Water Reuse: Potential for Expanding the Nation's Water Supply Through Reuse of Municipal Wastewater. Washington, DC: The National Academies Press. https://doi.org/10.17226/13303. 
Rana, S.U. (2019). Mission Paani: At least 300 lakes in and around Delhi have dried up due to rapid, unchecked urbanisation - India News, Firstpost. Retrieved February 14, 2021, from https://www.firstpost.com/india/mission-paani-at-least-300-lakes-in-and-around-delhi-havedried-up-due-to-rapid-unchecked-urbanisation-6976921.html

Reed, W. J., \& Heras, H. E. (1992). The conservation and exploitation of vulnerable resources. Bulletin of Mathematical Biology, 54(2-3), 185-207. https://doi.org/10.1007/BF02464829

Shan, L., Zhang, L., Song, J., Zhang, Y., She, D., \& Xia, J. (2018). Characteristics of dry-wet abrupt alternation events in the middle and lower reaches of the Yangtze River Basin and the relationship with ENSO. Journal of Geographical Sciences, 28(8), 1039-1058. https://doi.org/10.1007/s11442-018-1540-7

Singh, R. (2018). Sambhar: A Lake No More. Times of India. Retrieved February 14, 2021, from https://timesofindia.indiatimes.com/city/jaipur/sambhar-a-lake-nomore/articleshow/62552440.cms

Smith, T. (2012). Why are the world's lakes disappearing? Retrieved February 14, 2021, from https://www.climatechangenews.com/2012/02/29/why-are-the-worlds-lakes-disappearing/

Söderqvist, T. (2003). Are farmers prosocial? Determinants of the willingness to participate in a Swedish catchment-based wetland creation programme. Ecological Economics, 47(1), 105120. https://doi.org/10.1016/j.ecolecon.2002.09.004

Stirling, E., Fitzpatrick, R. W., \& Mosley, L. M. (2020, November 1). Drought effects on wet soils in inland wetlands and peatlands. Earth-Science Reviews, Vol. 210, p. 103387. https://doi.org/10.1016/j.earscirev.2020.103387

U.S. EPA. 2008. Methods for Evaluating Wetland Condition: Wetland Hydrology. Office of Water, U.S. Environmental Protection Agency, Washington, DC. EPA-822-R-08-024.

Wang, W., Lee, X., Xiao, W., Liu, S., Schultz, N., Wang, Y., ... Zhao, L. (2018). Global lake evaporation accelerated by changes in surface energy allocation in a warmer climate. Nature Geoscience, 11(6), 410-414. https://doi.org/10.1038/s41561-018-0114-8

Wang, M., Zhang, D., Dong, J., \& Tan, S. K. (2018). Application of constructed wetlands for treating agricultural runoff and agro-industrial wastewater: a review. Hydrobiologia, Vol. 805, pp. 1-31. https://doi.org/10.1007/s10750-017-3315-z

Wei, X., Khachatryan, H., \& Zhu, H. (2021). Poyang lake wetlands restoration in China: An analysis of farmers' perceptions and willingness to participate. Journal of Cleaner Production, 284, 125001. https://doi.org/10.1016/j.jclepro.2020.125001 
579 Table 1: Parameter values used in the numerical model

\begin{tabular}{|c|c|}
\hline Equations & Parameter Values \\
\hline$\pi_{t}=\pi_{0} q_{t} a_{t}$ & $\pi_{0}=100000 I N R / h a$ \\
\hline$m_{t}=\beta_{0} i_{t}^{\beta_{1}}$ & $\beta_{0}=1, \beta_{1}=37.5 \mathrm{MINR} / \mathrm{ha}$ \\
\hline$e_{t}=\min \left(b_{t} \gamma, r_{t} \varphi a_{t} \varepsilon\right)$ & $\gamma=456.25 \mathrm{ML} / \mathrm{ha} ; \varepsilon=0.01 * 365$ \\
\hline$v_{t}=v_{0}(1+\mu t) g \tau$ & $v_{0}=3 \mathrm{~mm} / \mathrm{day} ; \mu=0.2 \%$ \\
\hline$z_{t}=e_{t} p_{0}$ & $p_{0}=10000 I N R / M L$ \\
\hline$\dot{c}_{t}=\sigma$ & $\sigma=4$ tons $/$ ha \\
\hline$\dot{c}_{t}=-\omega \sigma$ & $\omega=1$ \\
\hline $\max _{i_{t}} \int_{0}^{\infty} y_{t} \exp (-\rho t) d t$ & $\rho=0.06$ \\
\hline$\dot{\lambda}=\lambda_{0} \cdot\left(1-\frac{\left(\frac{w_{t}}{w_{0}}\right)^{\epsilon_{0}}}{\left(\frac{w_{t}}{w_{0}}\right)^{\epsilon_{0}}+\epsilon_{1}}\right)$ & $\lambda_{0}=0.06 ; \epsilon_{0}=2 ; \epsilon_{1}=0.01$ \\
\hline$u_{\text {post }}=\int_{0}^{\infty}-s_{0} \omega \sigma g \exp (-\rho t) d t$ & $s_{0}=34 \mathrm{USD} /$ ton or $2380 \mathrm{INR} / \mathrm{ton}$ \\
\hline$x_{t}=\emptyset_{0} c_{t}^{\phi_{1}}$ & $\emptyset_{0}=1.9 ; \emptyset_{1}=0.79$ \\
\hline
\end{tabular}

580

581 


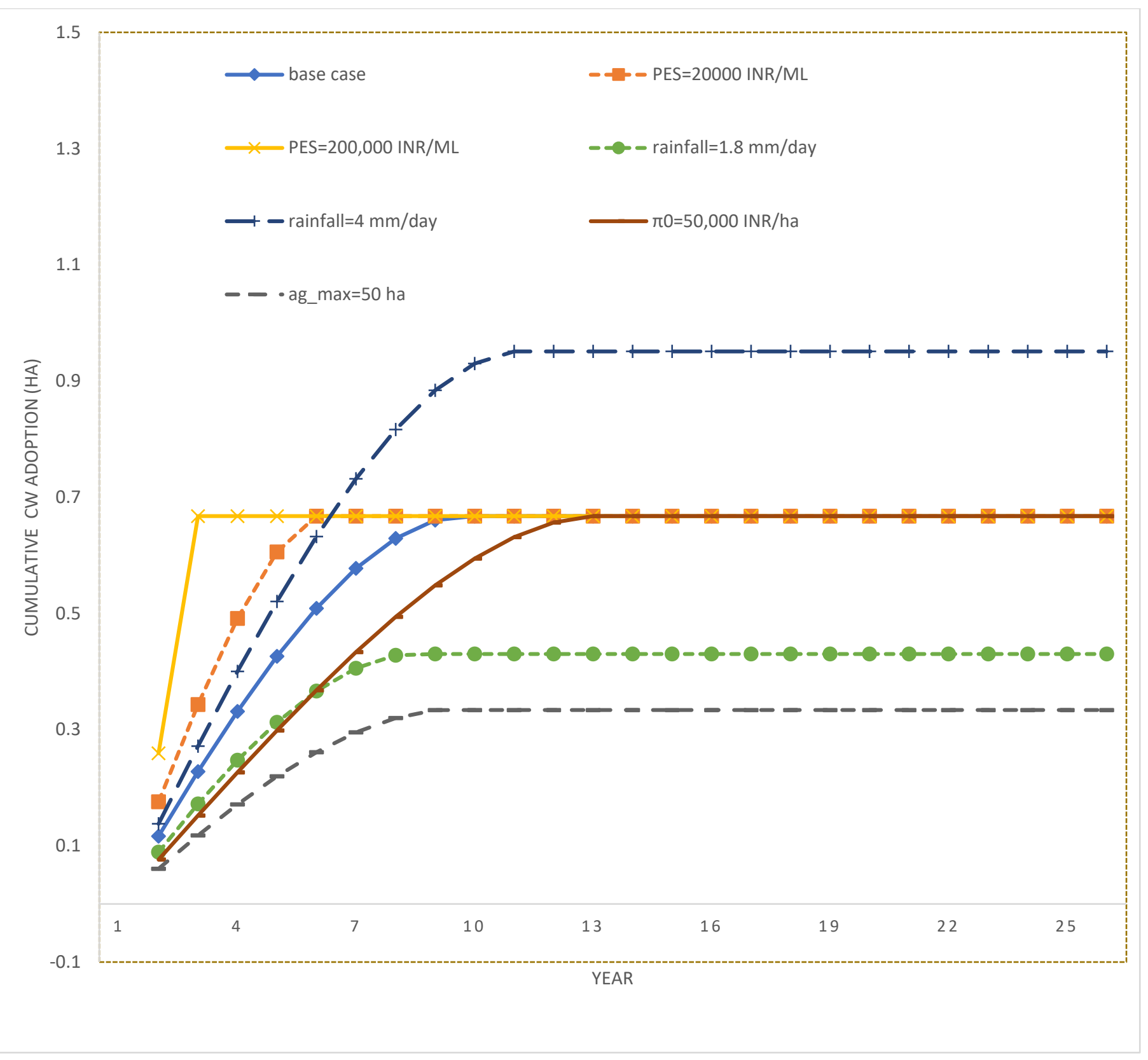

583 Figure 1: Time paths of cumulative total area brought under constructed wetlands under no-risk 584 scenarios 


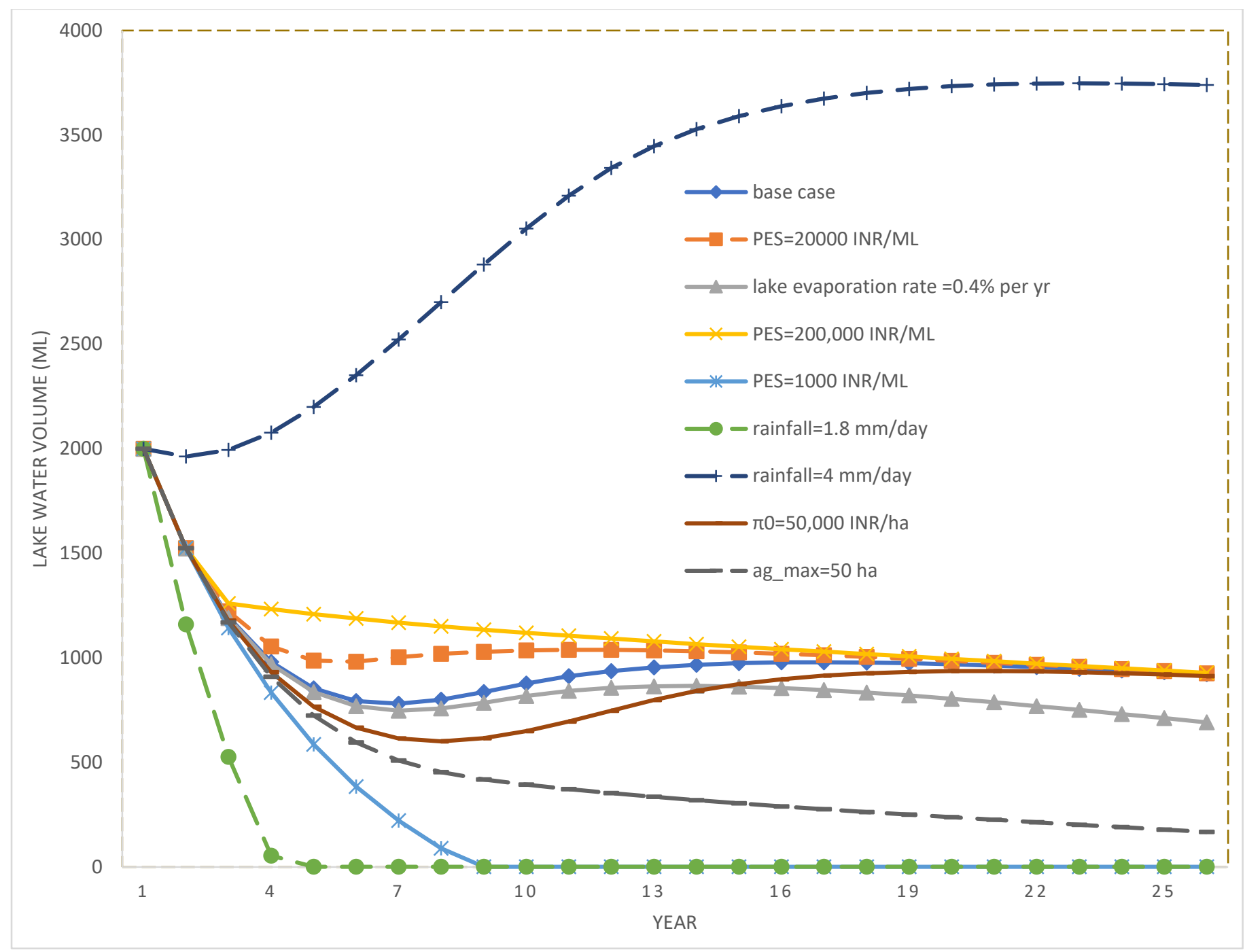

587 Figure 2: Time paths of cumulative total lake water volume under no-risk scenarios 


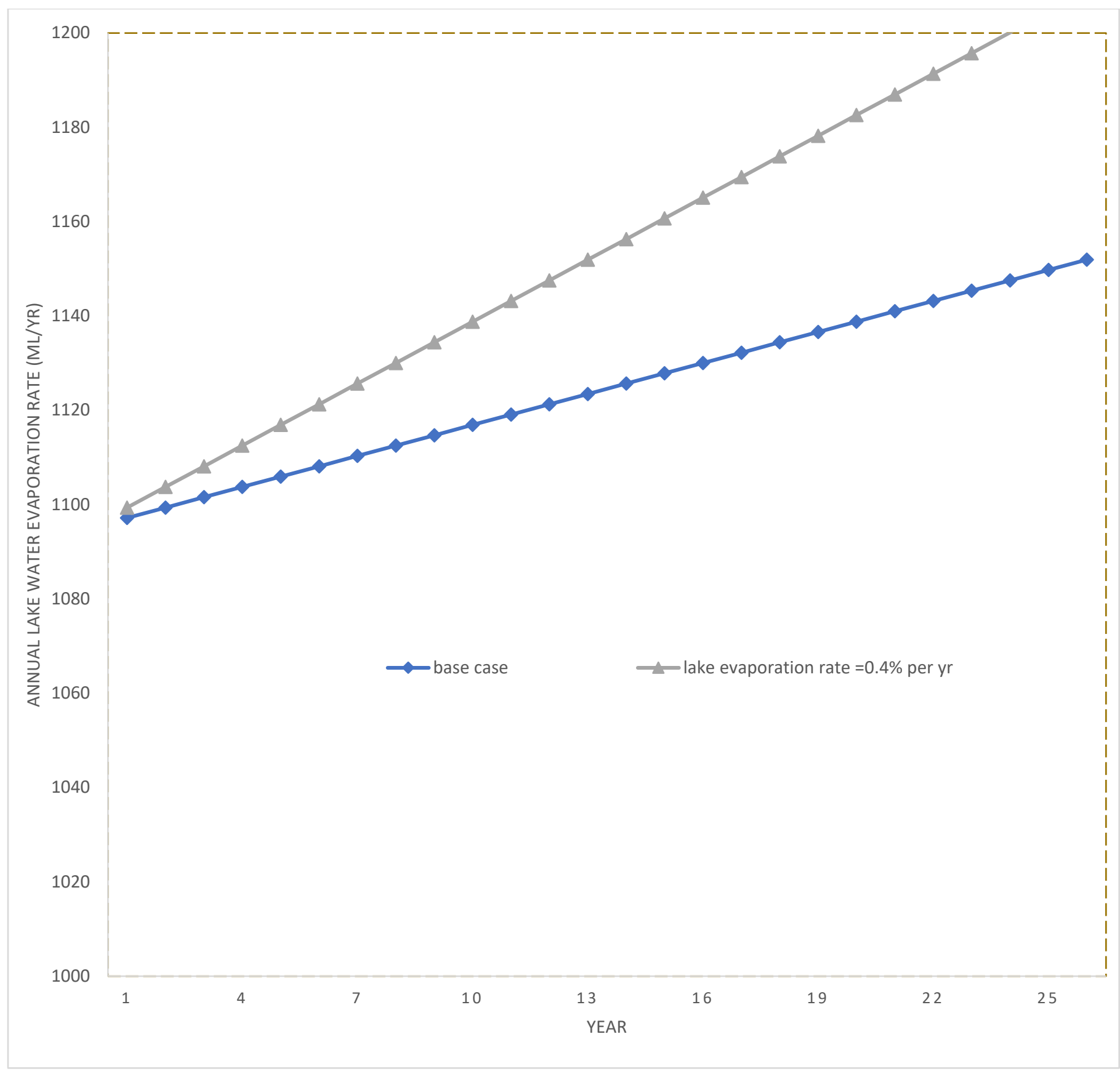

590 Figure 3: Time paths of annual rate of lake water evaporation (ML) under $0.2 \%$ and $0.4 \%$ annual 591 increase rates 


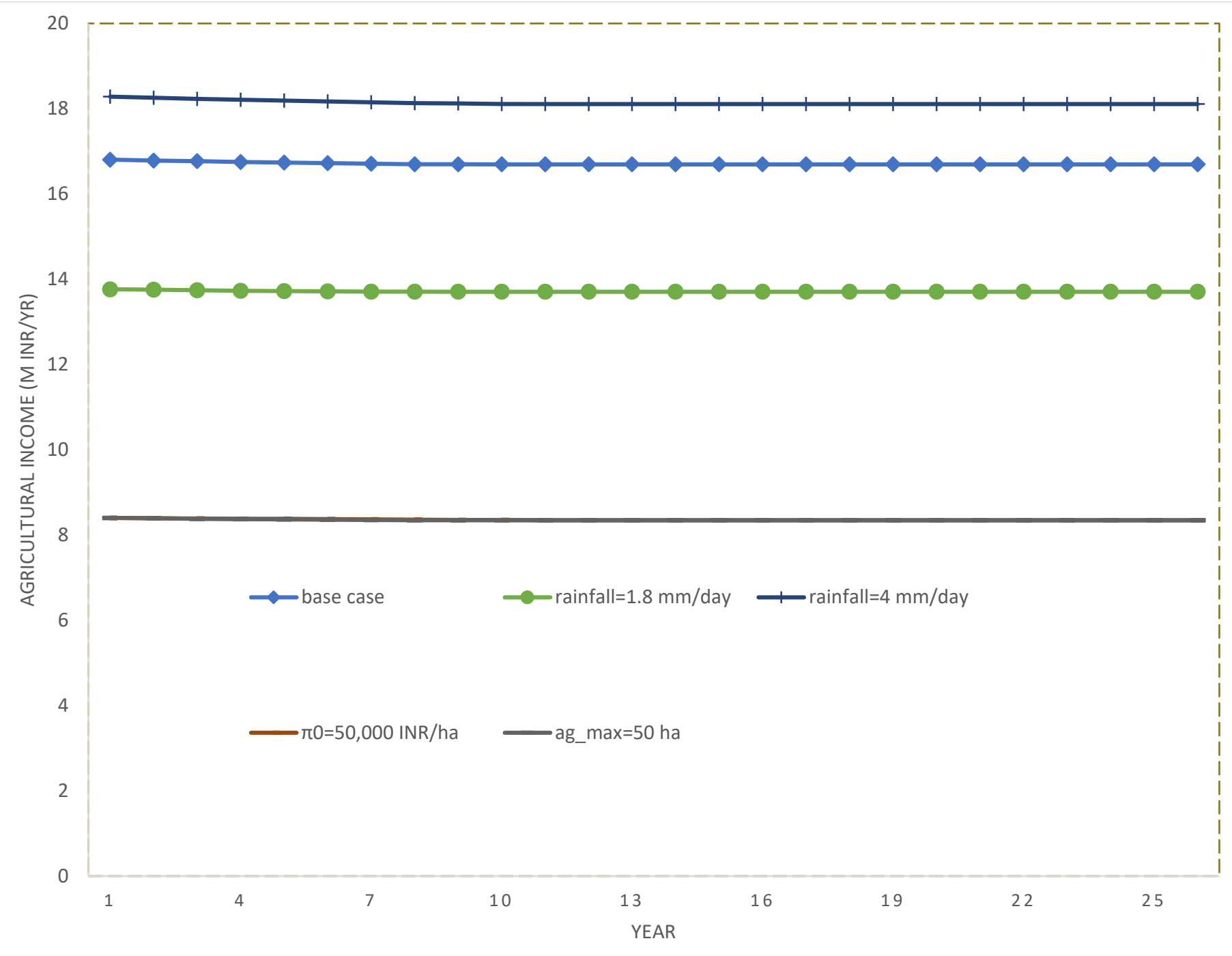

Figure 4: Time paths of annual agricultural incomes compared for no-risk scenarios 


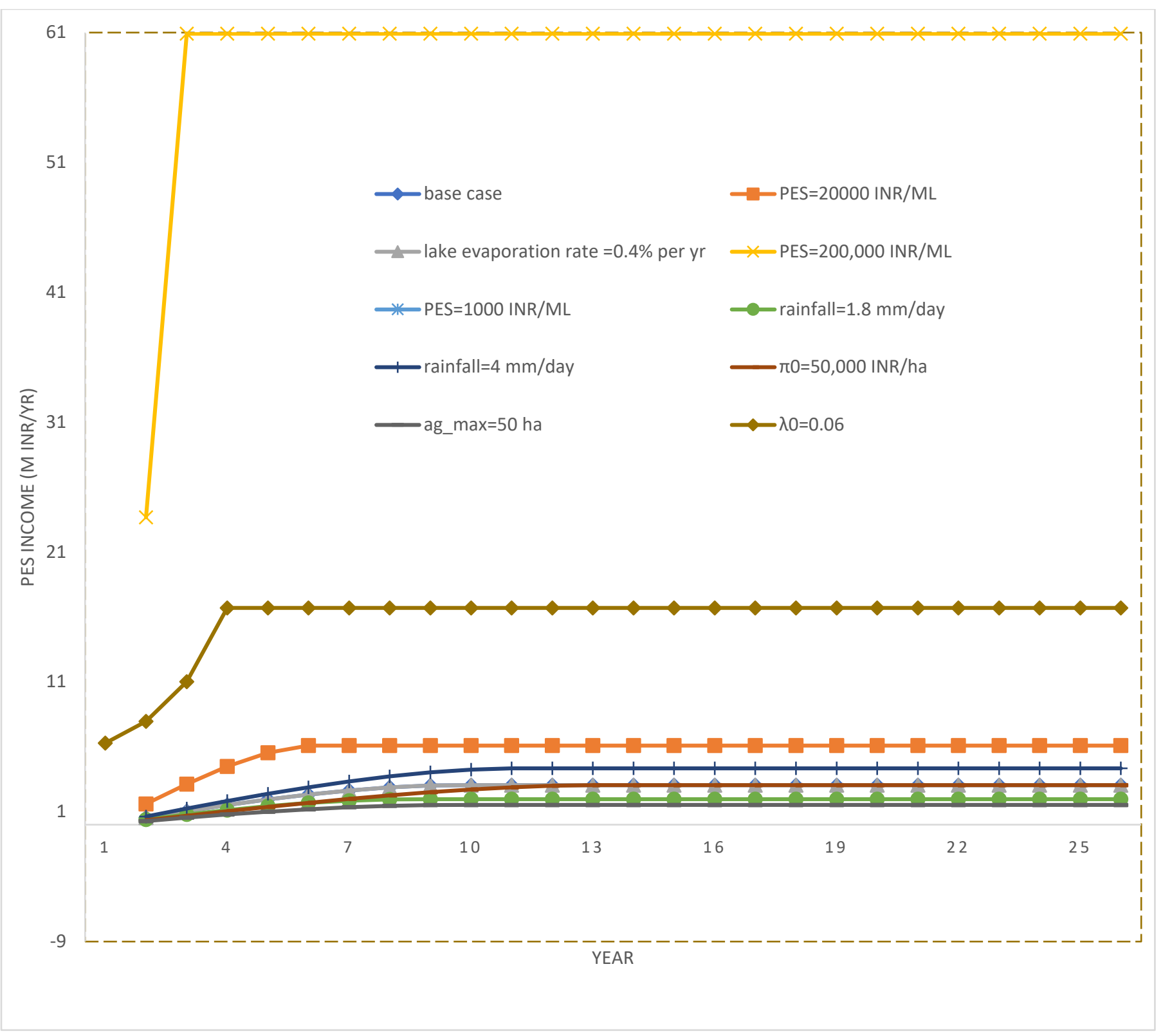

596 Figure 5: Time paths of annual income derived through PES payments under no-risk scenarios 


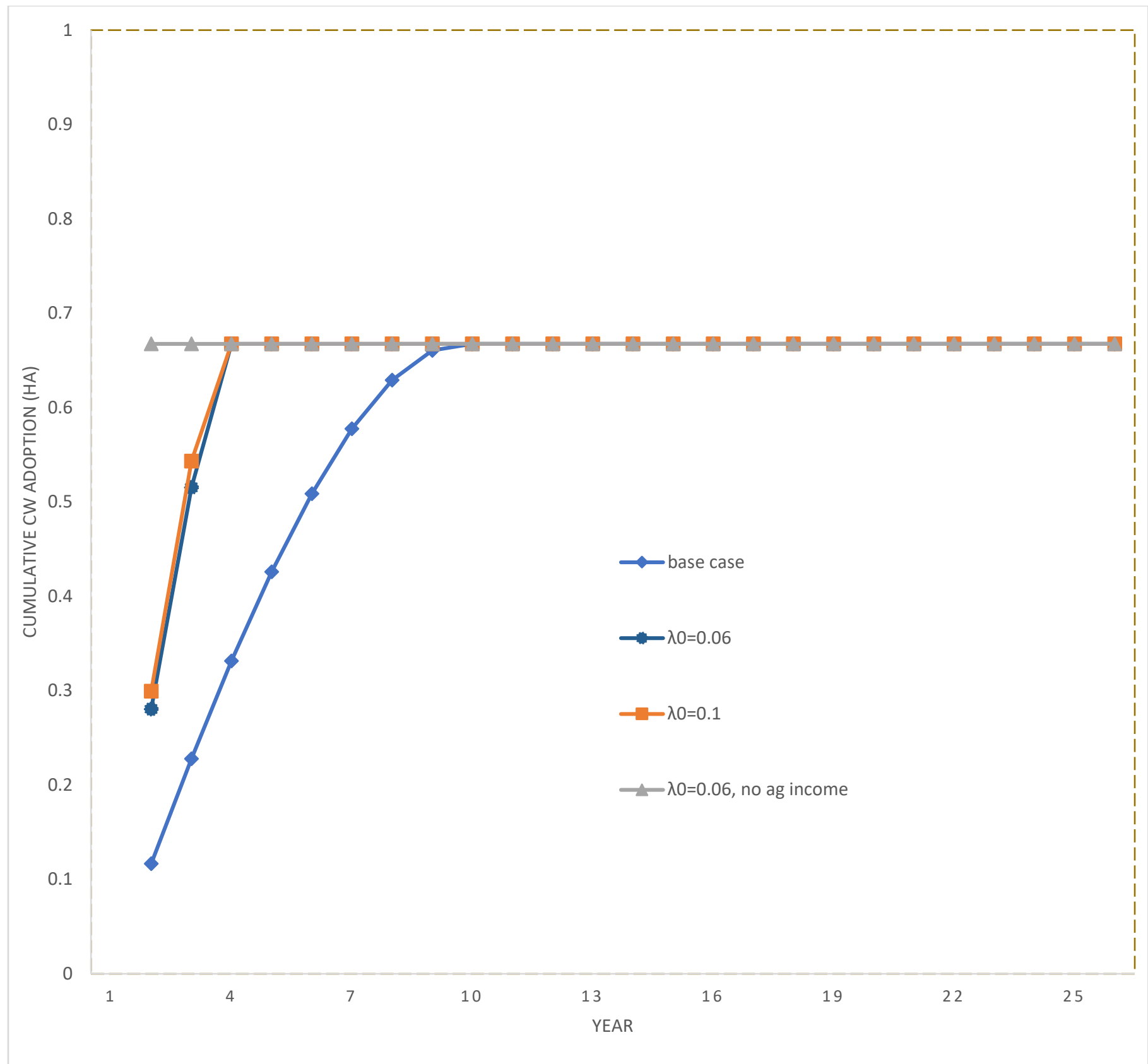

598

599 Figure 6: Time paths of cumulative total area brought under constructed wetlands under risk 600 scenarios

601 


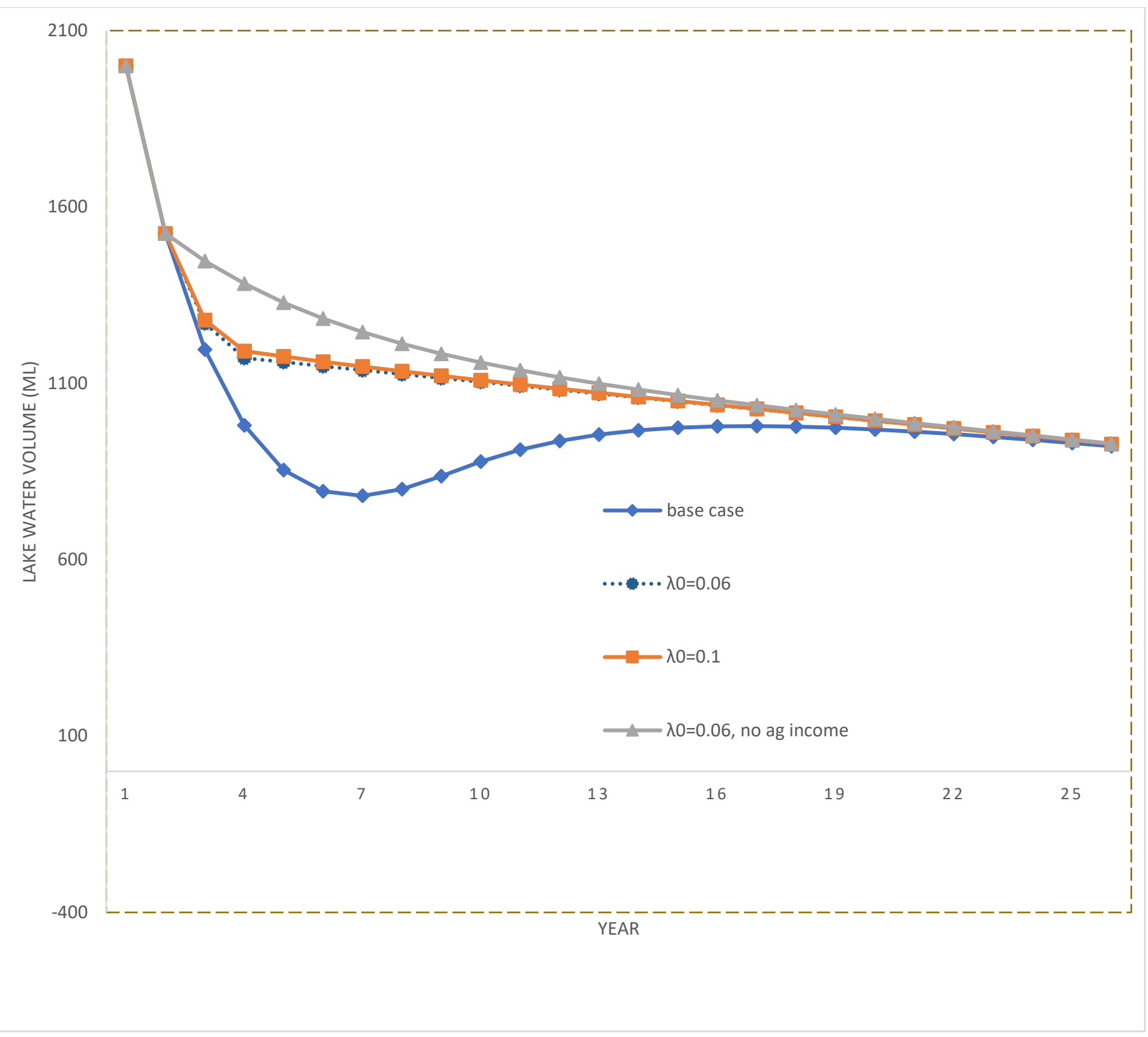

603 Figure 7: Time paths of cumulative lake water volumes (ML) compared for risk scenarios

604 


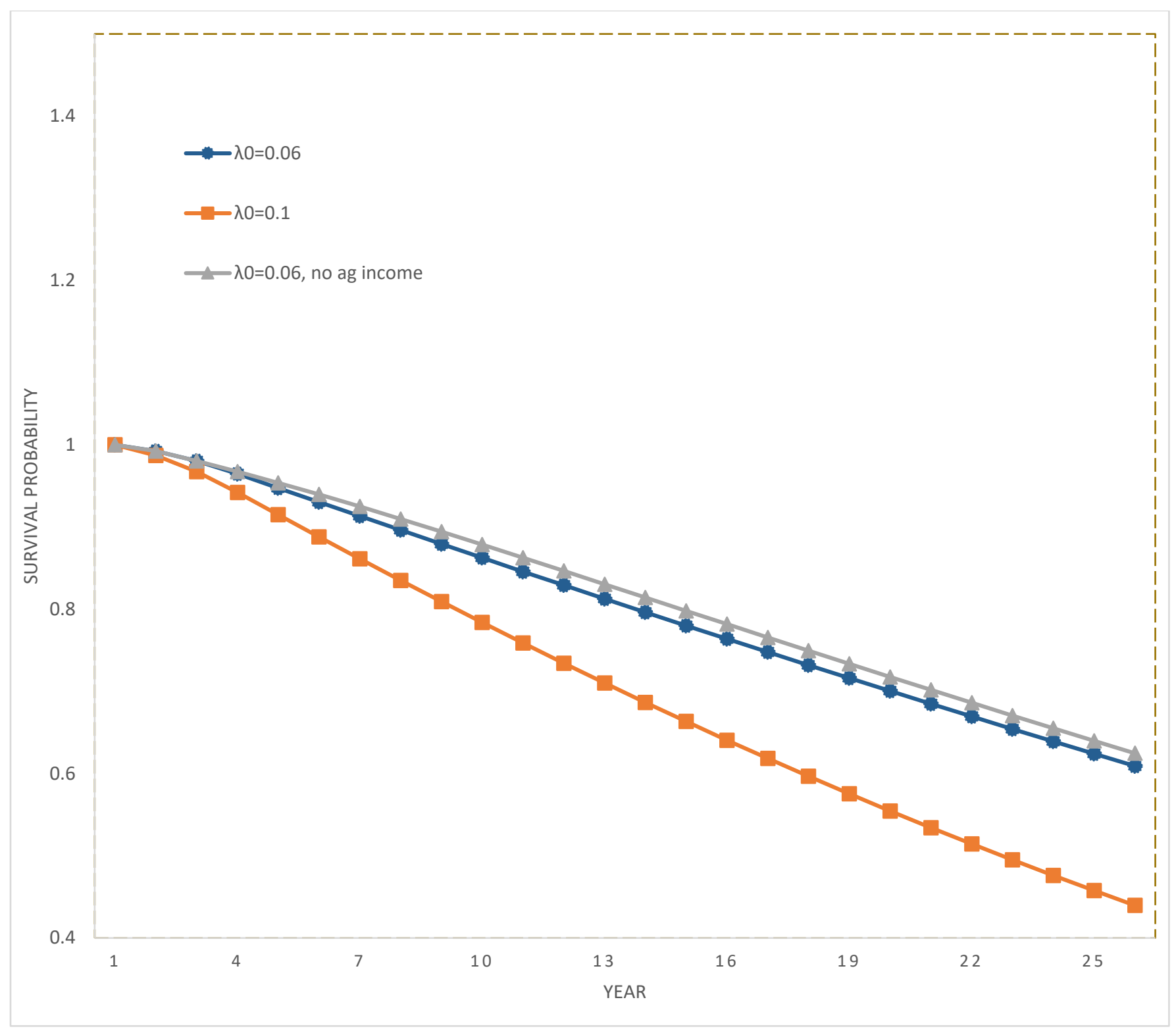

606 Figure 8: The probability that the lake will not turn dry until year $t$, depicted for lake drying risk 607 scenarios 
Figures

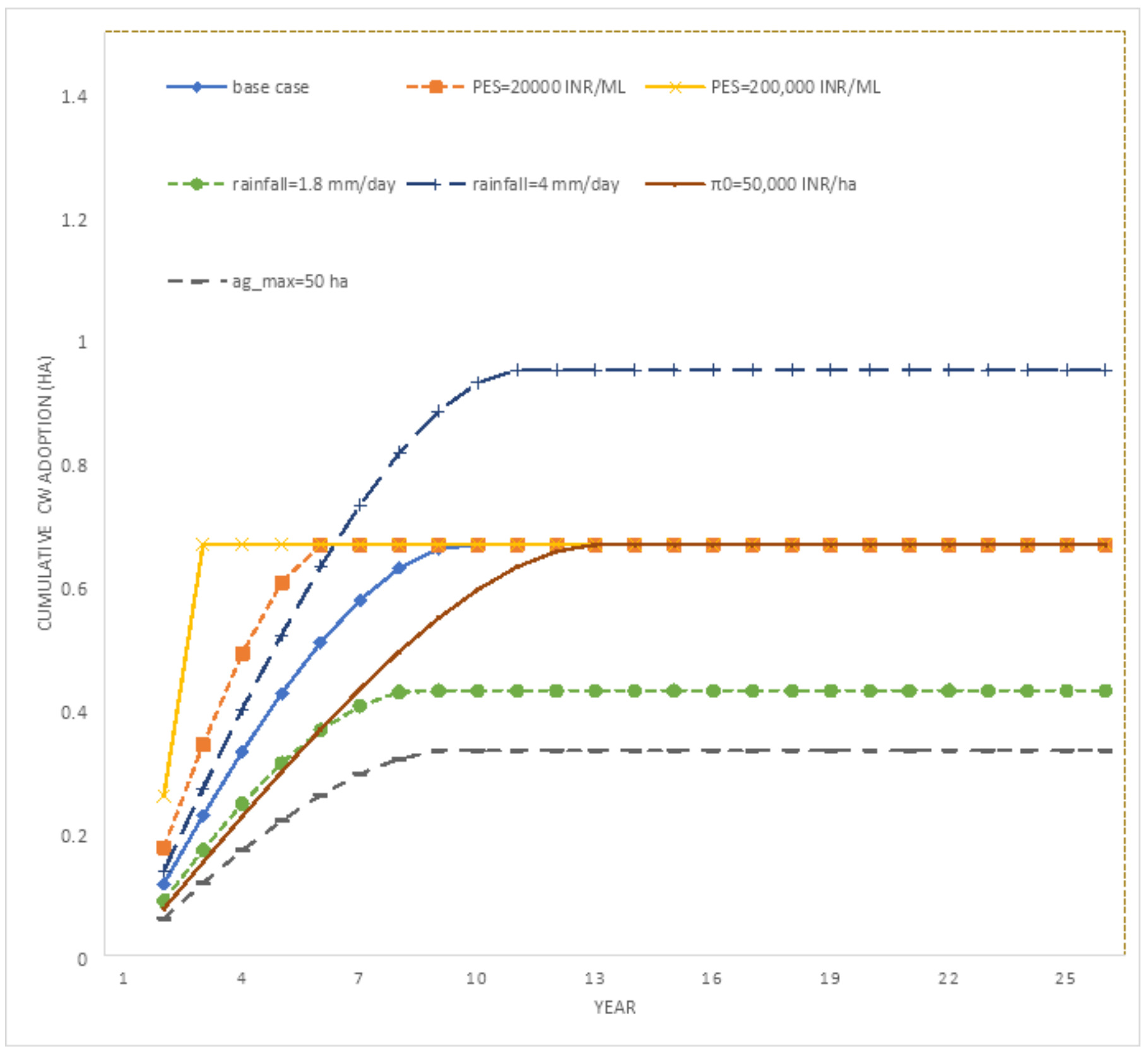

\section{Figure 1}

Time paths of cumulative total area brought under constructed wetlands under no-risk scenarios 


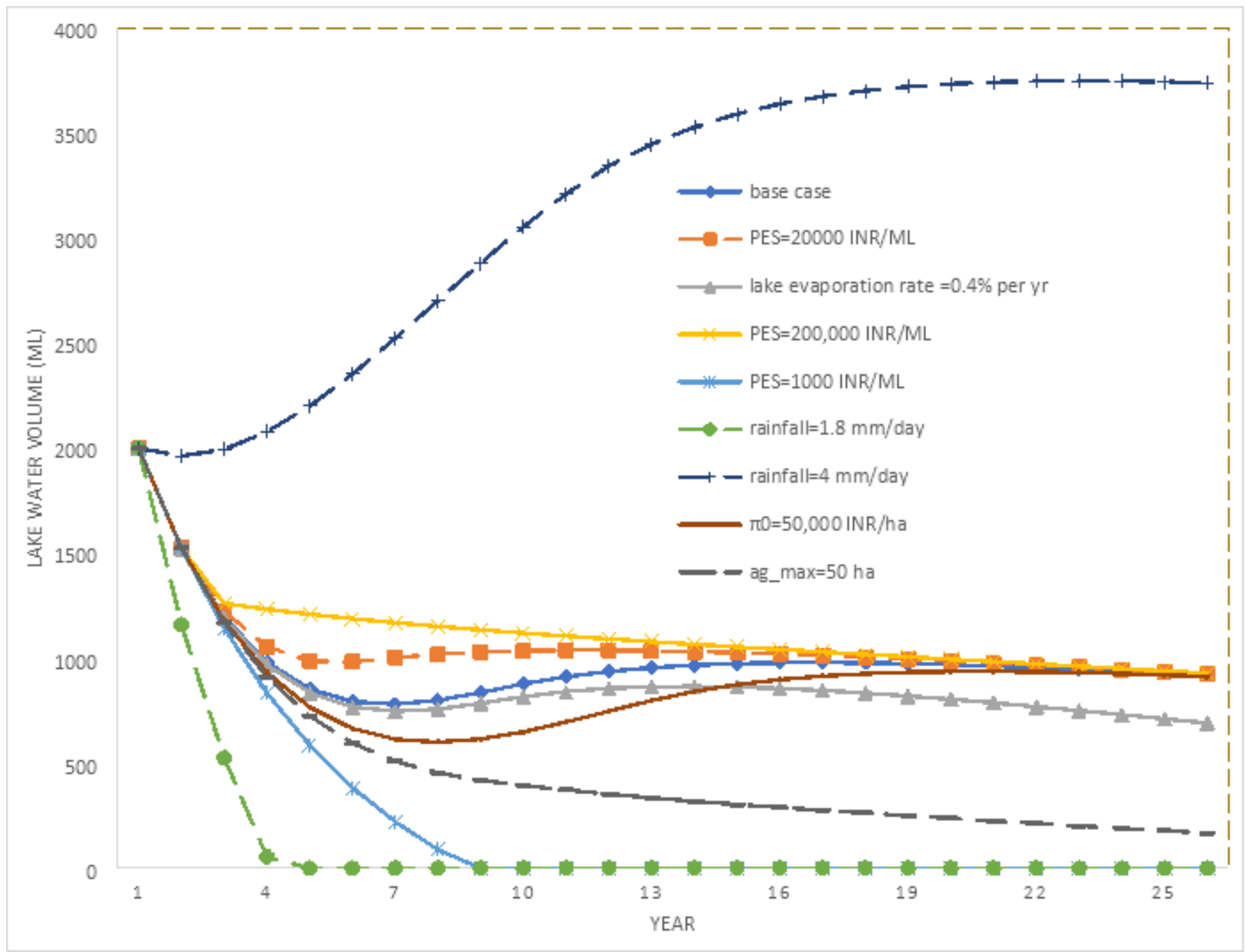

Figure 2

Time paths of cumulative total lake water volume under no-risk scenarios 


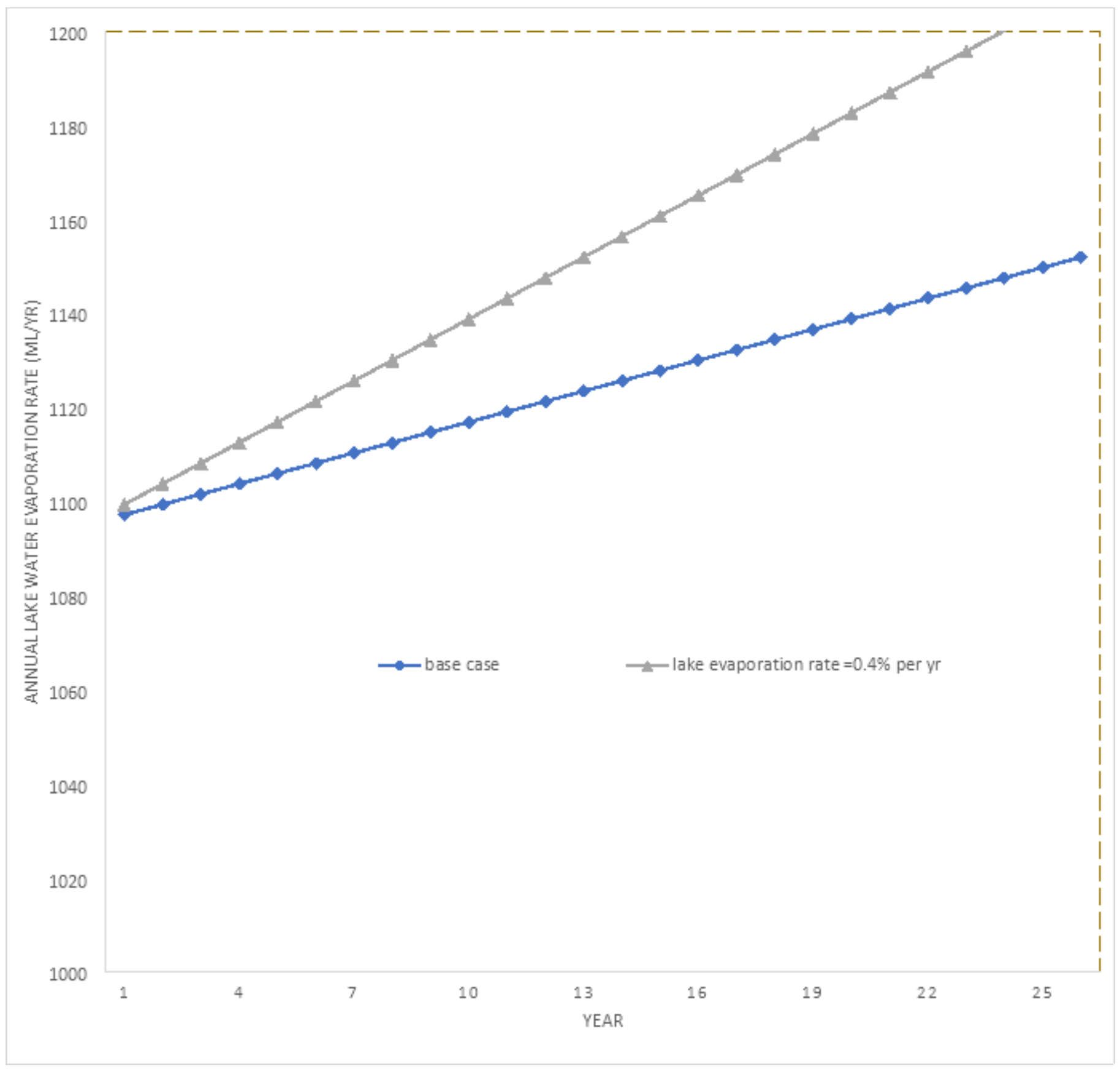

Figure 3

Time paths of annual rate of lake water evaporation $(\mathrm{ML})$ under $0.2 \%$ and $0.4 \%$ annual increase rates 


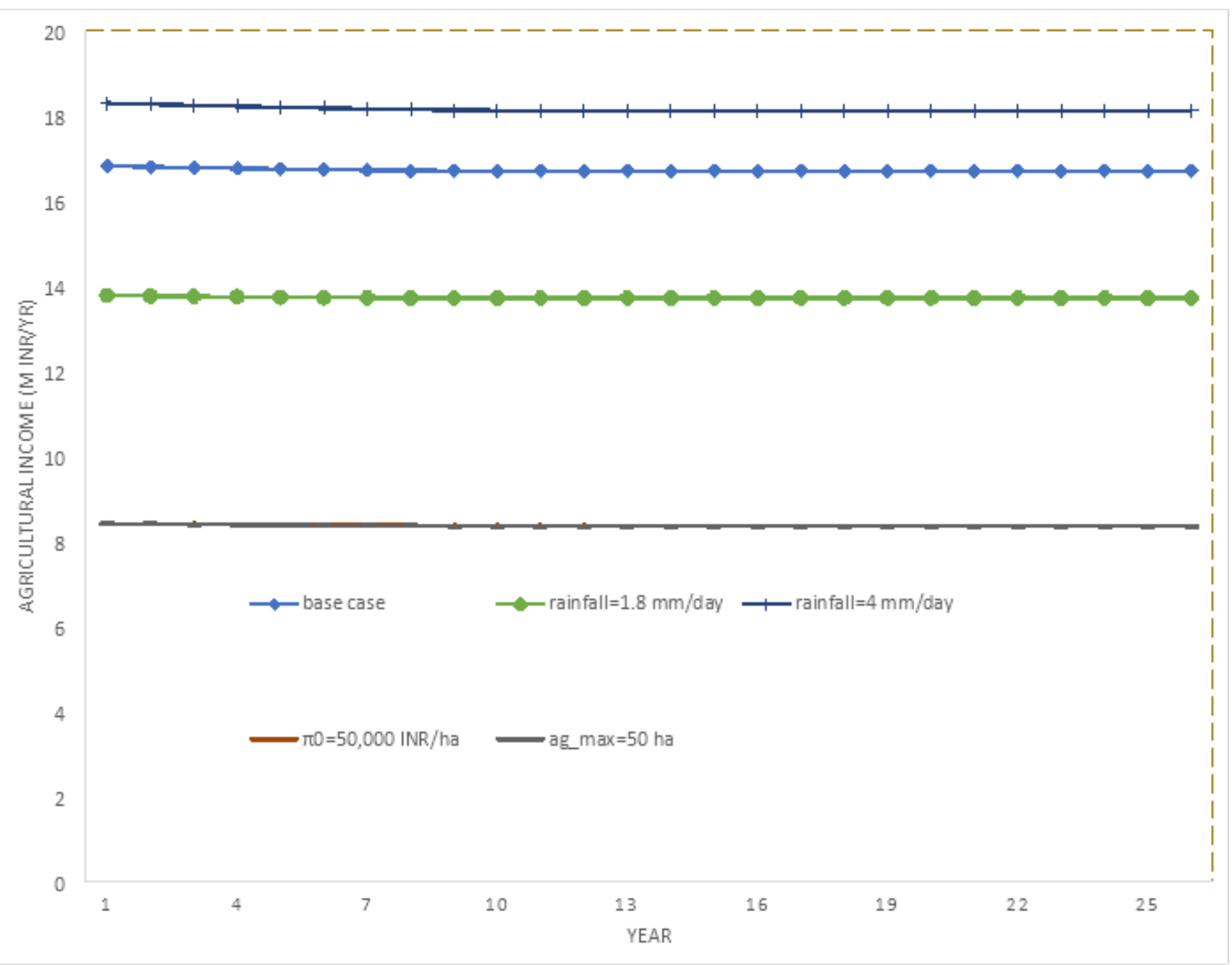

Figure 4

Time paths of annual agricultural incomes compared for no-risk scenarios 


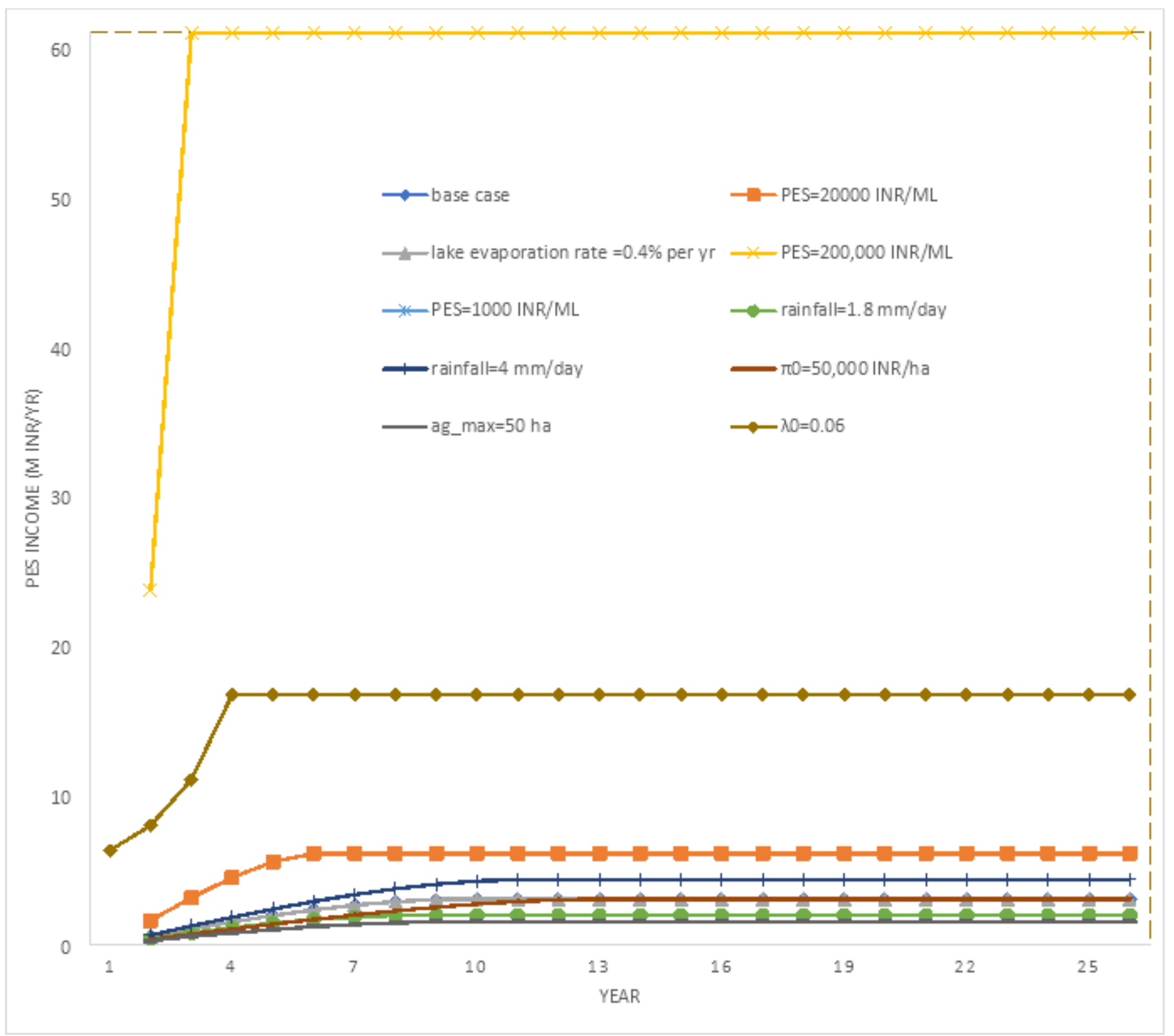

Figure 5

Time paths of annual income derived through PES payments under no-risk scenarios 


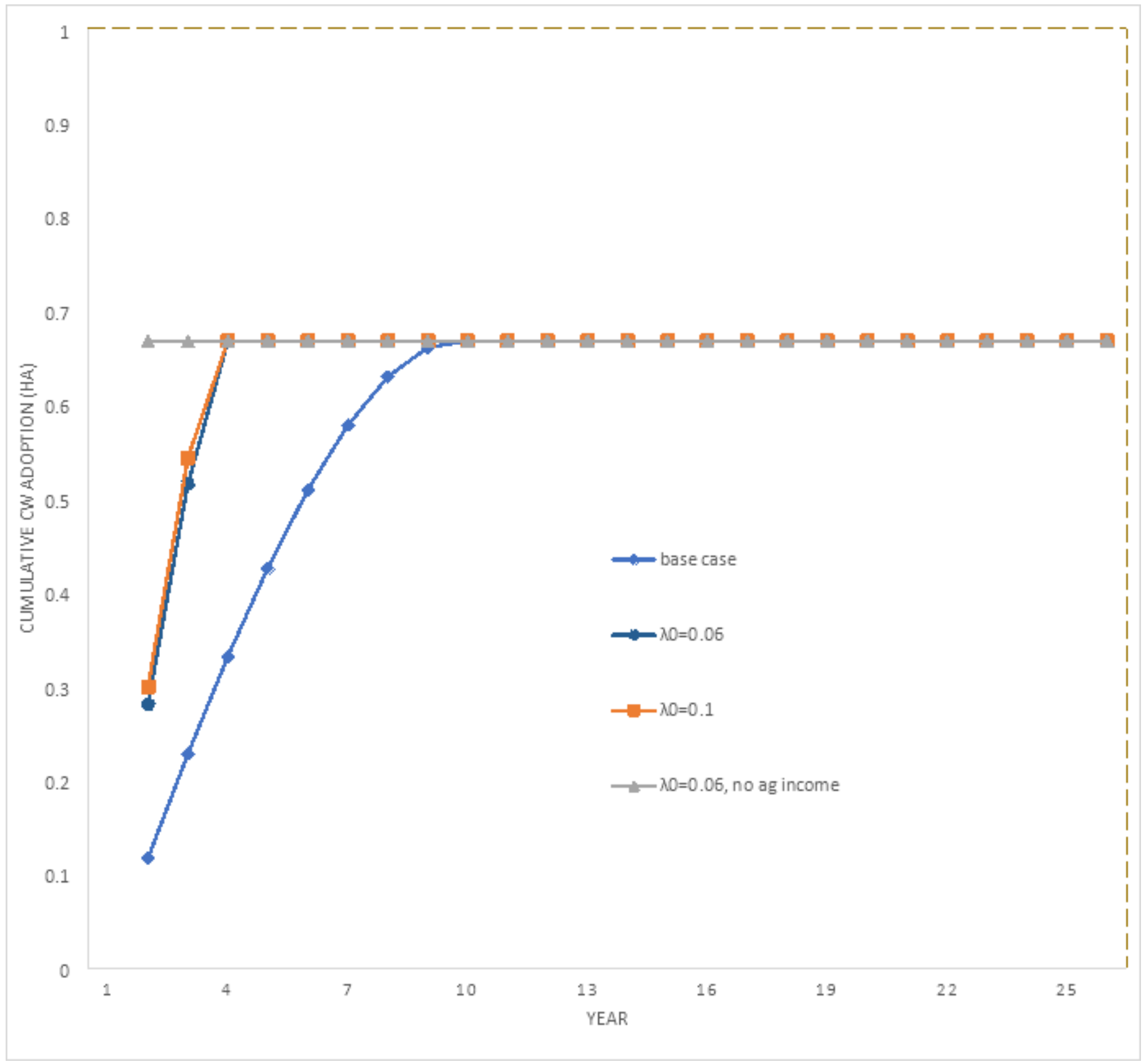

Figure 6

Time paths of cumulative total area brought under constructed wetlands under risk scenarios 


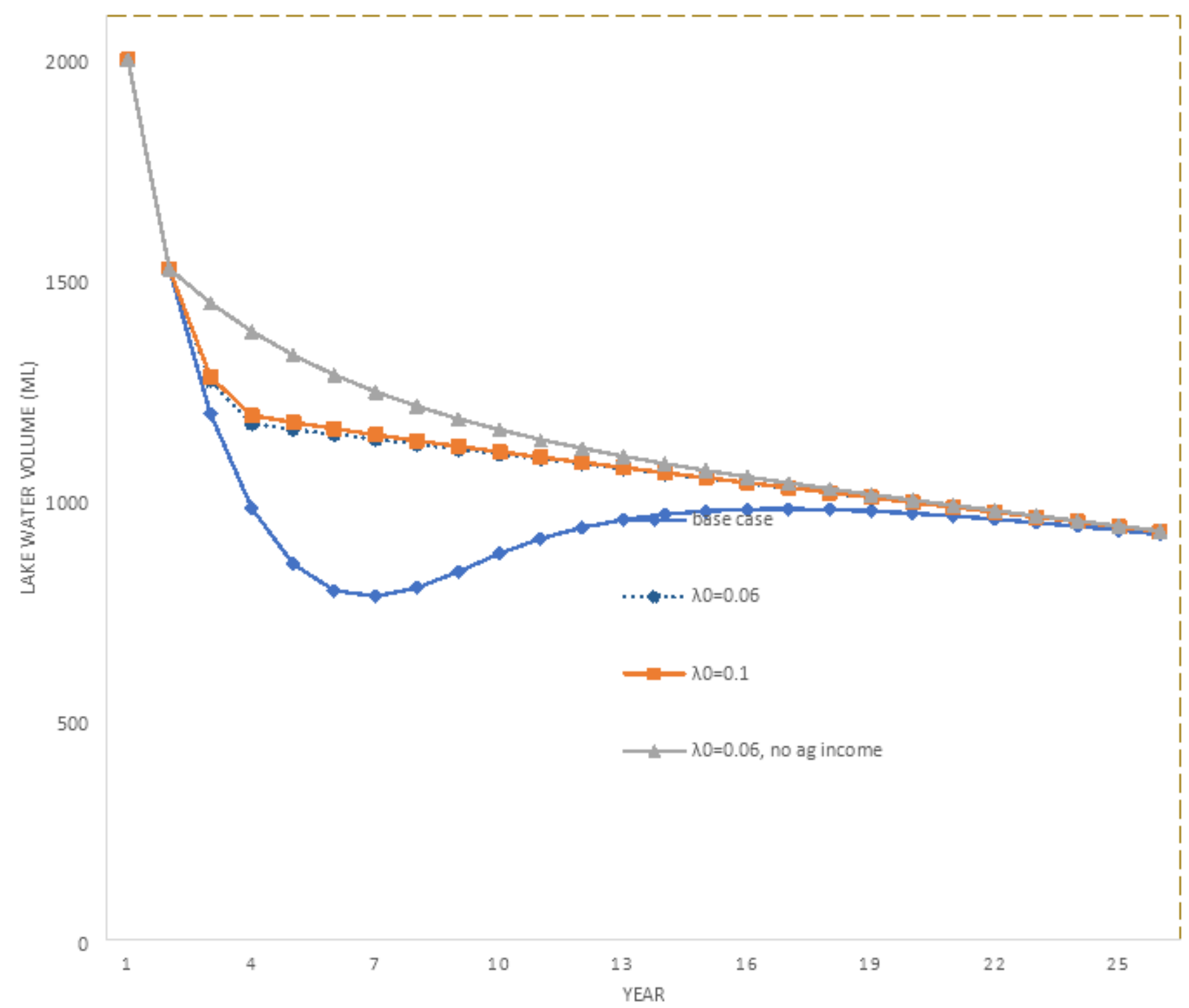

Figure 7

Time paths of cumulative lake water volumes $(\mathrm{ML})$ compared for risk scenarios 


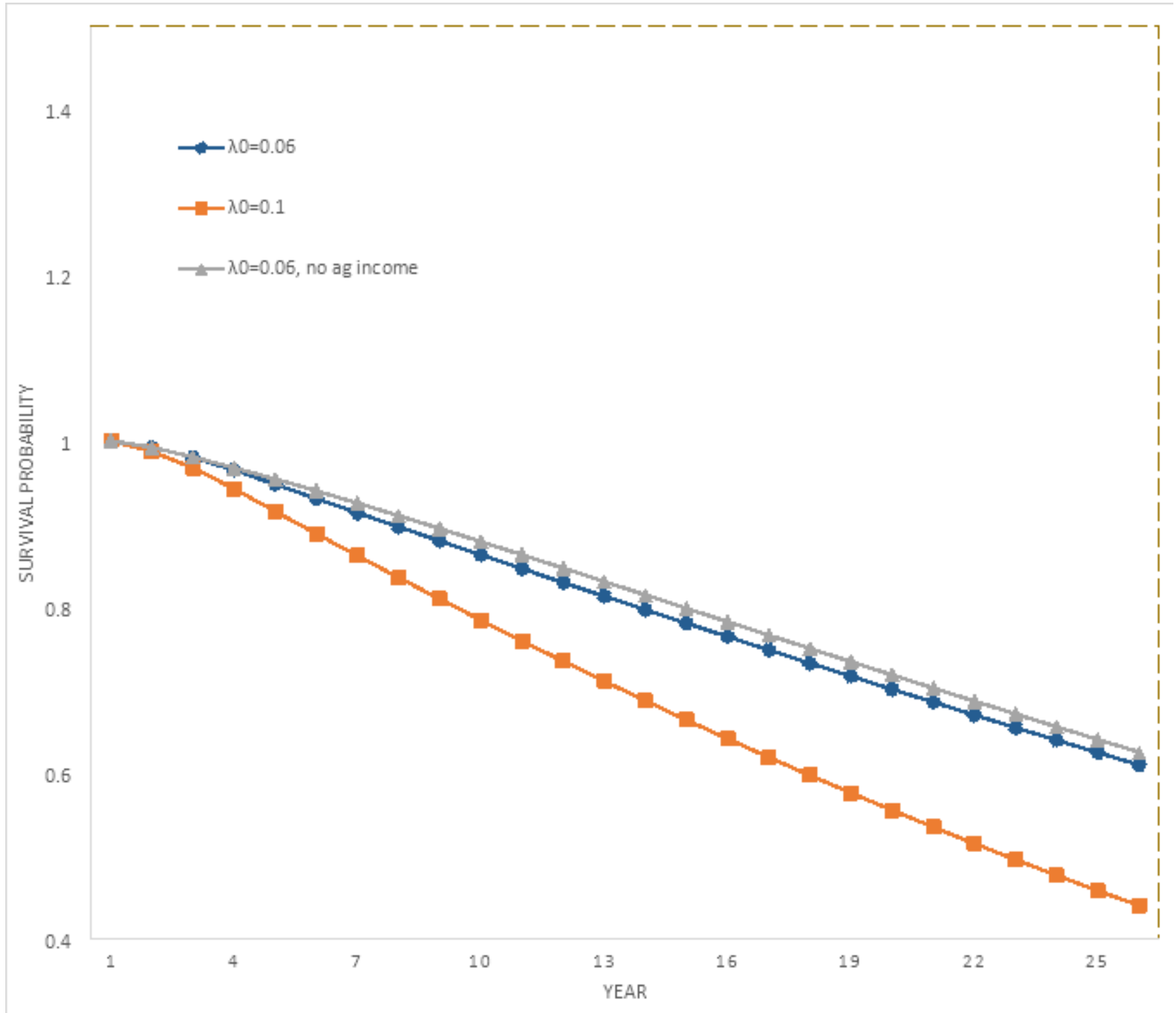

Figure 8

The probability that the lake will not turn dry until year $t$, depicted for lake drying risk scenarios 